\title{
Review: Enhancing gastrointestinal health in dairy cows
}

\author{
J. C. Plaizier ${ }^{1 \dagger}$, M. Danesh Mesgaran² ${ }^{2}$ H. Derakhshani ${ }^{1}$, H. Golder ${ }^{3}$, E. Khafipour ${ }^{1}$, J. L. Kleen ${ }^{4}$, \\ I. Lean ${ }^{3}$, J. Loor ${ }^{5}$, G. Penner ${ }^{6}$ and Q. Zebeli ${ }^{7}$
}

\begin{abstract}
${ }^{1}$ Department of Animal Science, University of Manitoba, Winnipeg, MB, R3T 2N2, Canada; ${ }^{2}$ Department of Animal Science, Ferdowsi University of Mashhad, Mashhad, 9177948974, Iran; ${ }^{3}$ Scibus, Camden, NSW, NSW 2570, Australia; ${ }^{4}$ Cowconsult, Coldinnerstrasse 65, 26532 Coldinne, Germany; ${ }^{5}$ Department of Animal Sciences, University of Illinois at Urbana-Champaign, Urbana, IL, 61801, USA; ${ }^{6}$ Department of Animal and Poultry Science, University of Saskatchewan, Saskatoon, SK, S7N 5A2, Canada; 'Department for Farm Animals and Veterinary Public Health, Vienna University of Veterinary Medicine, 1210, Vienna, Austria
\end{abstract}

(Received 14 December 2017; Accepted 19 June 2018; First published online 24 August 2018)

Due to their high energy requirements, high-yielding dairy cows receive high-grain diets. This commonly jeopardises their gastrointestinal health by causing subacute ruminal acidosis (SARA) and hindgut acidosis. These disorders can disrupt nutrient utilisations, impair the functionalities of gastrointestinal microbiota, and reduce the absorptive and barrier capacities of gastrointestinal epithelia. They can also trigger inflammatory responses. The symptoms of SARA are not only due to a depressed rumen $\mathrm{pH}$. Hence, the diagnosis of this disorder based solely on reticulo-rumen $\mathrm{pH}$ values is inaccurate. An accurate diagnosis requires a combination of clinical examinations of cows, including blood, milk, urine and faeces parameters, as well as analyses of herd management and feed quality, including the dietary contents of NDF, starch and physical effective NDF. Grain-induced SARA increases acidity and shifts availabilities of substrates for microorganisms in the reticulo-rumen and hindgut and can result in a dysbiotic microbiota that are characterised by low richness, diversity and functionality. Also, amylolytic microorganisms become more dominant at the expense of proteolytic and fibrolytic ones. Opportunistic microorganisms can take advantage of newly available niches, which, combined with reduced functionalities of epithelia, can contribute to an overall reduction in nutrient utilisation and increasing endotoxins and pathogens in digesta and faeces. The reduced barrier function of epithelia increases translocation of these endotoxins and other immunogenic compounds out of the digestive tract, which may be the cause of inflammations. This needs to be confirmed by determining the toxicity of these compounds. Cows differ in their susceptibility to poor gastrointestinal health, due to variations in genetics, feeding history, diet adaptation, gastrointestinal microbiota, metabolic adaptation, stress and infections. These differences may also offer opportunities for the management of gastrointestinal health. Strategies to prevent SARA include balancing the diet for physical effective fibre, non-fibre carbohydrates and starch, managing the different fractions of non-fibre carbohydrates, and consideration of the type and processing of grain and forage digestibility. Gastrointestinal health disorders due to high grain feeding may be attenuated by a variety of feed supplements and additives, including buffers, antibiotics, probiotics/direct fed microbials and yeast products. However, the efficacy of strategies to prevent these disorders must be improved. This requires a better understanding of the mechanisms through which these strategies affect the functionality of gastrointestinal microbiota and epithelia, and the immunity, inflammation and 'gastrointestinal-health robustness' of cows. More representative models to induce SARA are also needed.

Keywords: digestive tract, starch, microbiota, epithelium, acidosis

\section{Implications}

The common practice of feeding high grain diets to dairy cows can result in reversible rumen $\mathrm{pH}$ depressions, or subacute ruminal acidosis (SARA). This disorder reduces the gastrointestinal health by impairing nutrient utilisation, absorptive and barrier capacities of gastrointestinal epithelia and functionalities of gastrointestinal microbiota and causing inflammation, but these effects are not yet sufficiently

\footnotetext{
${ }^{\dagger}$ E-mail: Plaizier@umanitoba.ca
}

understood. Diagnosis of SARA requires a holistic evaluation of animal, diet, farm and management factors. Options for the prevention of SARA are available, including balancing the intakes of coarse fibre and rapidly degradable carbohydrates, especially starch, and the use of various feed supplements.

\section{Introduction}

Mulligan and Doherty (2008) described that high yielding dairy cows commonly suffer from production-limiting 
diseases including milk fever, ketosis, fatty liver, displaced abomasum and ruminal acidosis. They concluded that the causes for these diseases include 'a level of production inconsistent with nutrient intake, provision of an inadequate diet, an unsuitable environment, an inappropriate breeding policy or various combinations of these factors'. Many of these production-limiting diseases interact, and the prevention of one of these diseases cannot be achieved without also addressing the cow's gastrointestinal health (Enemark, 2008; Mulligan and Doherty, 2008; Plaizier et al., 2008). Gastrointestinal health encompasses the functionality of digesta, microbiota, and epithelial lining throughout the digestive tract (Plaizier et al., 2012b; Khafipour et al., 2016; Steele et al., 2016).

An aspect of gastrointestinal health that has received considerable attention is SARA, which is characterised by reversible rumen $\mathrm{pH}$ depressions, and often occurs after the replacement of course fibre by rapidly fermentable carbohydrates to meet high energy requirements (Kleen et al., 2003; Plaizier et al., 2008; Zebeli et al., 2012a and 2012b). The critical nature of SARA is evident, as the changes in metabolism in the reticulo-rumen as a consequence of this disease are involved in the etiopathogenesis of other diseases and disorders of cattle such as laminitis (Nocek, 1997), displaced abomasum (LeBlanc et al., 2005), unexplained body condition losses (Enemark, 2008), liver lipidosis (Ametaj et al., 2010), liver abscesses (Nagaraja and Lechtenberg, 2007) and milk fat depression (Bauman and Griinari, 2003; Kleen et al., 2003; Plaizier et al., 2008). Because of all of these consequences, SARA is considered an important productionlimiting disease of dairy cattle.

The term 'SARA' implies that the symptoms of this disease are caused by acidity in the reticulo-rumen. However, it has become evident that these symptoms are not solely due to this acidity, but that other conditions in the reticulo-rumen, and in other parts of the digestive tract, including the hindgut, also play a role (Bauman and Griinari, 2003; Khafipour et al., 2009a; Gressley et al., 2011). Hence, the term 'SARA' maybe misleading, and is not an accurate description for the disease. Another challenge to understanding the aetiology of this disease and its prevention is that the susceptibility to 'SARA' appears to vary among animals (Khafipour et al., 2009c; Penner et al., 2009; Plaizier et al., 2012b).

This review will focus on challenges to gastrointestinal health in cattle, with emphasis on dairy cows and on SARA, and on approaches to address these challenges. Various aspects of gastrointestinal health attributed or related to increases in the acidity of digesta and the susceptibility to these increases in ruminants will be discussed, including the functionalities of digesta, microbiota and epithelia. Underlying mechanisms of gastrointestinal health disorders will be discussed, as an understanding of these mechanisms is mandatory to develop effective treatment and prevention strategies. Finally, recommendations will be provided on how, despite the many nutritional challenges, gastrointestinal health in high yielding dairy cows can be maintained.

\section{Diagnosis and prevalence of poor gastrointestinal health}

Field studies on the prevalence of SARA have mostly used the rumenocentesis methodology of Garrett et al. (1999). Despite its common usage, this methodology was intended to differentiate rations that differed in their risk to cause a rumen $\mathrm{pH}$ depression, and not solely for the diagnosis of SARA. Hence, the thresholds proposed by Garrett et al. (1999) were the result of statistical analyses, and not of pathophysiological considerations. The methodology of Garrett et al. (1999) involves a sample size of 12 animals per herd and a pH threshold of 5.5 for the herd diagnosis of SARA. Data on using this methodology are available from the Netherlands (Kleen et al., 2009), Germany (Kleen et al., 2013), Italy (Morgante et al., 2007), United Kingdom (Atkinson, 2014), Iran (Tajik et al., 2009), Poland (Stefanska et al., 2017) and from Australia and Ireland as examples of grass-based systems (Bramley et al., 2008; 0'Grady et al., 2008). In the study of Kleen et al. (2009), for example, one farm had $38 \%$ of animals tested below pH 5.5, whereas on seven out of 18 farms, no cows had pH values below pH 5.5. The proportion of cows among all animals tested within a herd diagnosed with SARA varied among these studies from $11 \%$ (0'Grady et al., 2008) to $26 \%$ (Atkinson, 2014). A striking point is that all studies failed to mention and/or identify clinically discernible symptoms in cows or herds with low ruminal pH, except for low body condition scores. This poses the question if the rumenocentesis technique and daily spot rumen $\mathrm{pH}$ measurements are suitable for the diagnosis of SARA (see Supplementary Material S1). Nocek (1997) suggested that the nadir, or lowest point of the rumen $\mathrm{pH}$, is an accurate measure of the severity of the disease. However, it has been suggested that due to the diurnal fluctuation of the rumen $\mathrm{pH}$, the duration and areas below $\mathrm{pH}$ thresholds are more indicative of the severity of SARA (Plaizier et al., 2008; Zebeli et al., 2008; Petri et al., 2013). Gozho et al. (2007) used a threshold of a time below rumen pH 5.6 for more than $180 \mathrm{~min} /$ day for the diagnosis of SARA in rumencannulated cows with in-dwelling $\mathrm{pH}$ probes in their ventral rumen sacs, as more severe $\mathrm{pH}$ depressions resulted in increases in acute phase proteins in peripheral blood and endotoxins in rumen digesta. Continuous $\mathrm{pH}$ monitoring by ways of telemetry, however inaccurate it may be, has clearly helped to understand that the ruminal $\mathrm{pH}$ is more complex than thought previously and that 'snap-shot analyses' by ways of rumenocentesis show ruminal instability within herds rather than pointing to gastrointestinal problems of individual animals.

The thresholds of pH 5.6 and 5.8 consider that the functionality of many rumen bacteria is reduced when the rumen $\mathrm{pH}$ drops below these levels. This is related to the sensitivity of many enzymes produced and the reductions in bacterial growth at these low pH (Russell and Dombrowski, 1980; Shi and Weimer, 1992, see section on gut microbiota and gastrointestinal health). However, as functionality is shared by a variety of microbial taxa that differ in their acid sensitivity 
(Russell and Rychlik, 2001; Weimer, 2015), these thresholds will have to be revisited.

As the symptoms of SARA are not caused by a rumen $\mathrm{pH}$ depression alone, the diagnosis of SARA based solely on rumen $\mathrm{pH}$ values is not accurate. An accurate diagnosis requires a combination of clinical examinations of cows, as well as analyses of herd management and feed quality, including its chemical and physical properties (Kleen et al., 2003; Plaizier et al., 2008; Zebeli et al., 2012a). Next, to rumen $\mathrm{pH}$ values, several blood, milk, urine and faeces parameters, including their $\mathrm{pH}$ values, have been proposed for the diagnosis of SARA (Enemark, 2008; Plaizier et al., 2008; Danscher et al., 2015).

Impacts of induced SARA on milk fat have been shown in clinical studies (Enjalbert et al., 2008; Danscher et al., 2015). Bauman and Griinari (2003) reported that rumen pH depressions have long been associated with milk fat depression, but that the milk fat depression may not be directly caused by the low rumen $\mathrm{pH}$, and that the change in the biohydrogenation of unsaturated fat in the reticulorumen due to the rumen $\mathrm{pH}$ depression increases the concentrations of trans-octadecenoic acids, such as trans-10 cis-12 C18:2, and that these fatty acids inhibit de novo milk fat synthesis. Despite this, not all SARA inductions reviewed in Supplementary Material S2 resulted in a reduction in milk fat percentage. This could, in part, be due to the low number of replicates and the resulting low statistical power of most of these studies. However, the complexity of milk fat depression, including the existence of non-rumen $\mathrm{pH}$-related factors that cause this depression might also play a role. Hence, using milk fat depression as the sole measure for the diagnosis of gastrointestinal health diseases such as SARA is inaccurate. Nevertheless, using milk fat percentage as one of a combination of tools for this diagnosis is useful. Due to the effects of rumen $\mathrm{pH}$ depression on the fatty acid profile in milk (Bauman and Griinari, 2003), this profile, and especially the milk contents of odd and branch chain fatty acids, and the ratio between trans-10 C18:1/trans-11 C18:1 have also been recommended for the diagnosis of this $\mathrm{pH}$ depression (Enjalbert et al., 2008; Colman et al., 2013). However, many factors may affect the relationship between the fatty acid profile and the rumen $\mathrm{pH}$, and more research on these factors is needed before this profile can be recommended as a tool for the diagnosis of poor gastrointestinal health. A difficulty in using milk fat as a diagnostic tool in the field is that most diagnoses in the field have to rely on milk production data generated by milk recording and may, therefore, be inaccurate in terms of time and obtained too late. It appears possible that regularly obtained values created by realtime detection systems, as found in some automated milking systems, may overcome this dilemma. This option would require research actively using data from these milking systems and relate this data to results from direct $\mathrm{pH}$ measurement.

Various other biochemical analyses of milk, blood, urine or faeces, including their $\mathrm{pH}$, glucose, acute phase protein and endotoxin contents, have been evaluated for their accuracy in diagnosing SARA, but these have not proven to be sufficiently accurate (Enemark, 2008; Plaizier et al., 2008; Danscher et al., 2015). As gastrointestinal health affects feeding behaviour (Plaizier et al., 2008), monitoring this behaviour has been used as a diagnostic tool (DeVries and Chevaux, 2014; Braun et al., 2015). However, as cows vary in this behaviour, control values may have to be set for individual cows (Plaizier et al., 2008; Lean et al., 2014). More information on the diagnosis of acidosis is provided in the Supplemental Material S1.

\section{Diet and digesta composition and gastrointestinal health}

\section{Roles of structural and non-structural carbohydrates and proteins in the reticulo-rumen}

It is well recognised that the reticulo-rumen needs to be buffered to prevent undesirable increases in its acidity due to the production of organic acids during fermentation (Van Soest, 1994; Mertens, 1997; Plaizier et al., 2008). It is also well established that the dietary physically effective NDF (peNDF), that is, a fibre that stimulates chewing, saliva production and rumen buffering, is required for this (Plaizier et al., 2008; Zebeli et al., 2012a; Lean et al., 2014). The relationship between peNDF and rumen buffering is not yet well understood and defined, and not linear (Plaizier et al., 2008; Zebeli et al., 2012a; Lean et al., 2014). In addition, peNDF is required for the maintenance of the fibre mat in the reticulo-rumen (Zebeli et al., 2012a). This mat serves to retain small feed particles, that may otherwise escape the reticulo-rumen undegraded (Bhatti and Firkins, 1995; Tafaj et al., 2004). Increasing this escape alters the site and extent of degradation of nutrient in the digestive tract, and can have implications for the nutrient utilisation and health of the cow, such as hind gut acidosis (see the 'Hindgut fermentation' section). This shows that dairy cows diets need to contain sufficient peNDF. Zebeli et al. (2012a) concluded that the proportion of feed particles longer than $8 \mathrm{~mm}$ needed to be $>18.5 \%$ to prevent a rumen $\mathrm{pH}$ depression below 5.8 for more than $6 \mathrm{~h} /$ day.

Tafaj et al. (2004) investigated the composition and metabolism of different fractions of digesta in the reticulorumen of dairy cows and coined the term 'particle-associated rumen liquid' (PARL) for the proportion of rumen fluid attached to digesta particles found in the dorsal sac of the rumen. In contrast, the contents of the ventral sac were shown to mainly consist of extensively digested, smallsized, potentially escapable particles, suspended in the free rumen liquid (FRL; Tafaj et al., 2004). Numerous studies (Tafaj et al., 2004; Li et al., 2009) reported differences in the concentrations and metabolisms of microorganism between PARL and FRL in the ventral rumen sac. The FRL had a different microbial composition, as well as lower concentrations of volatile fatty acids (VFA) and a higher $\mathrm{pH}$ than PARL. Despite this, the FRL is the most investigated phase of the reticulo-rumen, and the effects of high-grain 
diets on the characteristics of PARL are not yet well understood.

Next, to the dietary contents of non-fibre carbohydrates (NFC) and starch, the dietary contents of non-starch NFC also affect gastrointestinal health and nutrient utilisation. Hall and Weimer (2016) observed that the in vitro utilisation was highest for glucose, followed by fructans and inulin and that the microbial protein yield was $20 \%$ greater for fructans and inulin compared with glucose. Mojtahedi and Danesh Mesgaran (2011) partially substituted dietary starch with pectin by replacing barley grain with sugar beet pulp and concluded that this increased chewing, rumen $\mathrm{pH}$ and nutrient digestibility. Another mechanism through which replacing starch with sugars may enhance rumen health and nutrient utilisation, is that this stimulates butyrate production, and, thereby, the energy supply to and functionality of the rumen epithelium (Dionissopoulos et al., 2013; Malhi et al., 2013). Golder et al. (2014b and 2014c) also observed that sugars differ in their effect on reticulo-rumen function, including the production of lactic acid.

Most experimental inductions of SARA used a combination of feed restriction, increased grain feeding and reduced feeding of peNDF (Supplementary Material S2, Kleen et al., 2003; Krause and Oetzel, 2005; Plaizier et al., 2008). The amount and rumen degradability of the grain, the abruptness and duration of the increased grain feeding, and the reduction of the dietary peNDF varied greatly among studies, which challenges comparisons among these studies. The starch content of the SARA-inducing diets were around the top end of what has been observed on commercial dairy farms with high yielding cows (Plaizier et al., 2004; Dann, 2010; Senaratne et al., 2016). As on farms, SARA is likely caused by a combination of high grain and low peNDF feeding (Kleen et al., 2003 and 2013). The effects of inducing SARA by high grain feeding are more severe than that induced by a low peNDF feeding (see 'Diagnosis and prevalence of poor gastrointestinal health on dairy farms' section, Khafipour et al., 2009a and 2009b; Kleen et al, 2013). Hence, the effects of most experimentally-induced SARA may be more severe than those of on-farm SARA. Thus, experimental methods that more closely represent SARA on dairy farms are needed. These methods will need to adopt a combination of feed restriction, and low, respectively, high, dietary contents of coarse fibre and starch.

Differences in ruminal responses to different grain species and cultivars, as well as to different processing techniques are evident (Lean et al., 2013). This includes differences among grains in rumen $\mathrm{pH}$ response over time, in propionate, valerate and ammonia concentrations in the rumen and differs in acidosis risk. Sensible approaches to controlling the risk include testing for quality, rumen degradability and/or risk of acidosis (a near IR reflectance test has been developed for this purpose); establishing a regular supply from a consistent source; and careful and consistent processing of grain. Use of by-products of human food production including flour and maize manufacturing processes and distilling wastes and fats to maintain the energy density of the diet and to control starch and sugar intakes are strategies employed to reduce the risk of acidosis and potentially increase the profitability of production (Lean et al., 2013; Golder et al., 2014b and 2014c).

Guidelines for the dietary structural and non-structural carbohydrates contents that optimise productivity and animal well-being while reducing the risk of rumen acidosis are provided in the Supplementary Material S3. Of these, the guidelines for dietary starch and peNDF are considered the most critical, but they are not generally agreed upon, likely to general and in need of urgent updating. Also, other techniques for the measurement of peNDF are needed, as factors other than feed particle size, including the fragility of feed particles, also affect the ability of a feed to stimulate chewing and rumen buffering (Plaizier et al., 2008; Zebeli et al., 2012a).

\section{Rumen metabolomic alterations and implications for cattle health}

Metabolomics technology has become an important part of livestock science to better understand health and disease (Goldansaz et al., 2017). Compared with classical onemetabolite one-biochemical reaction studies, high-throughput metabolomic technologies provide broader information of metabolic pathways in (microbial) cells, allowing the establishment of metabolic patterns in a complex system, such as the gastrointestinal ecosystem. Ametaj et al. (2010) and Saleem et al. (2012) performed comprehensive studies characterising the bovine ruminal fluid metabolome combining several technologies, such as ${ }^{1}$ Proton nuclear magnetic resonance (1H-NMR), Gas chromatography-mass spectrometry, direct flow injection-mass spectrometry, inductively coupled plasma mass spectrometry, with computer-aided literature mining. These studies quantified a large spectrum of metabolites in the bovine ruminal fluid. In addition, they reported potentially toxic biomarkers in the rumen fluid of dairy cows that experienced SARA after being fed barley grain-rich diets. Feeding such diets is, therefore, accompanied with the release of various metabolic compounds, including methylated amines as well as bacterial cell wall components, such as endotoxins, that may be toxic to the host, and may have implications on the overall health of dairy cows. More specifically, these data indicated that cows fed $45 \%$ barley grain (60\% concentrate in dry matter) had higher concentrations of methylamine, endotoxin, ethanol, xanthine, $\mathrm{N}$-nitrosodimethylamine, 3-phenylpropionate in their rumen fluid. A similar conclusion was reported in a recent study with dairy cows (Zhang et al., 2017).

There are indications that the toxins associated with high grain diets, including endotoxins, secondary metabolites and microbial-associated molecular patterns, can interact with the epithelia and translocate into systemic and lymphatic circulation (Aschenbach et al., 2003; Khafipour et al., 2009a). In the Ussing chamber system, Emmanuel et al. (2007) demonstrated that endotoxins translocate across the rumen wall at a greater rate than across the colon wall. Alternately, it was observed that at acidic pH values on the 
mucosal side increased the permeability of ${ }^{3} \mathrm{H}$-mannitol more than fivefold to sixfold through colon and rumen tissues, respectively (Emmanuel et al., 2007). Research by Aschenbach et al. (2000) demonstrated that the permeability of rumen epithelia to histamine, another polyamine linked to high grain feeding and bovine laminitis (Nocek, 1997), increased when $\mathrm{pH}$ declined. Thus, SARA conditions can lead not only to the generation of multiple toxic compounds in the rumen but also predisposes translocation of these compounds across the gastrointestinal tract epithelia (see the 'The role of the rumen and hindgut epithelia in gastrointestinal health' section).

\section{Hindgut fermentation}

Hindgut fermentation has been associated with high intake of starches and other fermentable substrates that are not fully digested in the upper gastrointestinal tract (Gressley et al., 2011). Feeding of large amounts of grain, and conditions when the rumen mat does not function properly, such as during SARA conditions, inevitably lead to larger amounts of fermentable substrates that by-pass rumen fermentation. Cattle have limited amylolytic activity in the small intestine (Matthé et al., 2001), and incompletely degraded substrates, most importantly starches, are fermented in the hindgut, increasing the risk of hindgut acidosis. Emerging evidence suggests that hindgut diseases may afflict the health status of cattle the same way as rumen diseases (Gressley et al., 2011; Steele et al., 2016).

The mechanisms of $\mathrm{pH}$ regulation in the hindgut are unexplored. The ability of the hindgut to self-regulate $\mathrm{pH}$ is limited, mainly due to a lack of salivary buffering and the protozoa (Gressley et al., 2011). However, similar to the reticulo-rumen, an anion exchange (AE) resulting in the release of bicarbonate exists. In the reticulo-rumen, protozoa modulate bacterial metabolism and are able to remove starch from the milieu and, therefore, stabilise the $\mathrm{pH}$. Hence, the absence of protozoa in the hindgut increases the percentage of the total available substrate for bacterial fermentation, and, potentially, the variation in $\mathrm{pH}$ (Van Soest, 1994). Comparisons of the nutrient absorption pathways of the reticulo-rumen and the hindgut have also shown that, while there are functional similarities in metabolic signatures, the complements of host genes which are involved are not highly similar (Metzler-Zebeli et al., 2013). Also, the values of $\mathrm{pH}$ viewed as thresholds of SARA in the rumen $(\mathrm{pH}$ at 5.6 in Gozho et al., 2007; or 5.8 in Zebeli et al., 2008) are much lower than those of acidosis in the hindgut (typically at a range of 6.0 to 6.6; Metzler-Zebeli et al., 2013), indicating different mechanisms and development bases of ruminal acidosis compared hindgut acidosis.

The intestinal mucosa is comprised a monolayer rather than of a stratified epithelium, as in the rumen. The simpler histological structure makes the hindgut epithelium more susceptible to the acidic damage, barrier damage and translocations of toxins than the rumen (Li et al., 2012a; Tao et al., 2014). However, this susceptibility may be attenuated by the mucous secretion that protects the epithelia that exists in the large intestine, but not in the reticulo-rumen (Van Soest, 1994). Nevertheless, Emmanuel et al. (2007) reported a higher translocation of endotoxin across colon epithelia compared with rumen epithelia. The concentration of endotoxin in the large intestine can exceed values recorded from the same subjects in the reticulo-rumen (Li et al., 2012; Metzler-Zebeli et al., 2013). Thus, microbial dysbiosis and epithelial damage in the hindgut can lead to systemic translocation of bacteria and toxins resulting in similar symptoms than SARA (Plaizier et al., 2008; Plaizier et al., 2012b; Zebeli and Metzler-Zebeli, 2012). Hence, several symptoms that are attributed to adverse conditions in the rumen may be the result of adverse conditions in the hindgut.

Despite the importance of the hindgut in nutrition and health of cattle, the effects of diet composition on hindgut fermentation have been largely overlooked. Also, comparatively little is known about the mucosal adaptation of the hindgut in cattle in response to an energy-enhanced nutritional plane. This lack of knowledge hampers the development of efficient and sustainable strategies to modulate metabolism and health of the hindgut, which are needed to improve overall health and productivity of cattle. The difficulty of obtaining samples from the hindgut and the lack of models to simulate hindgut fermentation are also reasons why only limited research has been conducted in the hindgut, especially regarding influences of nutrition on the epithelial function and host-microbiota interaction. By understanding the underlying mechanisms of $\mathrm{pH}$ regulation, cellular communication and hindgut microbiome and host interaction in the hindgut, it will be possible to understand and better manage complex digestive diseases in cattle.

\section{Gut microbiota and gastrointestinal health}

\section{Overview and biotic perturbants of gut microbiota}

Ruminants, including cattle, rely on symbiotic microbial communities within the digestive tract for the utilisations of their dietary nutrients (Flint and Bayer, 2008). These symbionts are comprised of anaerobic fungi, archaea, bacteria and viruses. The stability of the reticulo-rumen and hindgut ecosystems rely on the ecological properties of its resident microbiota (Khafipour et al., 2016). Both reticulo-rumen and hindgut harbour an immense species- and strain-level diversity with overlapping metabolic capabilities (Khafipour et al., 2016; Plaizier et al., 2017). However, the number of substrate degradation points that are essential to fundamental reticulo-rumen fermentation processes are modest, resulting in the presence of between tens and hundreds of bacterial species with the potential enzymatic activity required for each degradation point (Weimer, 2015). Hence, despite of high inter-animal differences in the composition of rumen microbiota, the presence of a 'core microbiome' ensures that the reticulo-rumen ecosystem is functionally redundant and capable to carryout main metabolic activities that are essential for the survival of the ruminant host (Khafipour et al., 2009c; Plaizier et al., 2017). Another important characteristic of the reticulo-rumen and hindgut 
ecosystems is the resilience of its microbial symbionts against perturbations by biotic (e.g. exogenous microbes) and abiotic (e.g. changes in the nutrient profile, pH) stresses. From an ecological perspective, resilience is the amount of stress or perturbation that a system can tolerate before it changes from one stable equilibrium state to another (Folke et al., 2004). Overall, the reticulo-rumen and hindgut microbiomes, owing to their complex composition and functional redundancy, are robust against these perturbations (Weimer, 2015). However, the type of microbial response depends on the intensity and nature of the perturbants (Golder et al., 2014b and 2014c; Khafipour et al., 2016).

Changes in diet composition and exposure to exogenous (allochthonous) microbes originating from the diet and environment are important factors that can expose the reticulo-rumen and hindgut microbiota to perturbations (Khafipour et al., 2016). The ability of exogenous microbes to integrate into and colonise the reticulo-rumen niche is limited by competing resident (autochthonous) members that are adapted to the environment of the rumen (Weimer, 2015). Food-born microbes may integrate into the gastrointestinal microbiomes and constitute a 'transient microbiome' that has the ability to affect the functionality of the microbial community (Derrien and van Hylckama Vlieg, 2015). These changes are usually temporary. However, the presence of open niches where an exogenous strain is capable to metabolise biomolecules that are non-degradable by, or even toxic to, other reticulo-rumen microbes can be an exception to this, and result in the successful integration and establishment of this strain in the reticulo-rumen ecosystem (Weimer, 2015).

\section{Effects of high-grain feeding on gut microbiota}

Apart from biotic perturbants, abiotic stresses, including those induced by high-grain feeding, have the ability to temporarily or permanently change the composition and functionality of reticulo-rumen and hindgut microbiota (Khafipour et al., 2009c; Derakhshani et al., 2016; Plaizier et al., 2017). Abrupt changes in the nutrient, and especially the carbohydrate, composition of the diet can rapidly affect the reticulo-rumen microbiota. This, in turn, may alter biochemical parameters of the reticulo-rumen and hindgut ecosystems (Fernando et al., 2010; Li et al., 2012; Plaizier et al., 2017). Studies have shown that excessive grain feeding and the resulting ruminal acidosis reduce the richness, evenness and diversity of microbiota, and the abundances of many beneficial microbial taxa in the reticulo-rumen (Khafipour et al., 2009c and 2016; Mao et al., 2013) and in the hindgut (Plaizier et al., 2017). Members of gut microbiota differ in their functionality and ability to utilise different groups of substrates (Henderson et al., 2015). Hence, a higher richness and diversity of these microbiota enable a more efficient use of nutrient resources, and enhance their stability, and are, therefore, most often beneficial (Russell and Rychlik, 2001; Ley et al., 2006). Thus, the reductions in richness and diversity of gastrointestinal microbiota that occur during high-grain feeding and SARA suggest that these microbiotas are transformed into less functional and desirable state (Plaizier et al., 2017). There may, however, be exceptions to this as functionality is shared by a variety of microbial taxa (Russell and Rychlik, 2001; Weimer, 2015)., Hence, these changes do not have to be reflective of changes in the functionality of these microbiota. (The compositions of microbiota vary within the reticulo-rumen. In the lumen of a healthy reticulo-rumen, bacteria belonging to the Firmicutes and Bacteroidetes phyla dominate. Particle-associated microbes, such as Ruminococcus spp. and Fibrobacter succinogenes, play a central role in biofilm formation and sequential breakdown of cellulosic biomass, especially in the fibre mat (Leng, 2014). The microbiome of the liquid fraction is dominated by amylolytic and proteolytic bacteria of the Bacteroidetes phylum, including Prevotella spp. (McCann et al., 2014). The rumen tissue-associated/epimural microbiota, similar to the mucosa-associated microbiota in other compartments of the gastrointestinal tract, contain a high proportion of bacteria belonging to Proteobacteria (Derakhshani et al., 2016). This may be due to the presence of aerotolerant bacterial lineages among the members of this phyla that play a role in reducing the oxygen that diffuses from the blood to the epithelium, and, thereby, maintain the anaerobic ecosystem of the reticulo-rumen (Albenberg et al., 2014).

High grain feeding and a resulting grain-induced SARA decrease the relative abundance of Bacteroidetes and increase that of Firmicutes in the luminal content of the reticulo-rumen, resulting in a dysbiotic community and a potential loss of community function (Khafipour et al., 2009c; Mao et al., 2013; Petri et al., 2013). White et al. (2014) concluded that Firmicutes differ from Bacteroidetes in how they degrade plant biomass in the reticulo-rumen. Firmicutes degrade cell surfaces, whereas the degradation by Bacteroidetes is mainly periplasmic and intracellular. El Kaoutari et al. (2013) reported that, on average, Firmicutes encode fewer glycan-cleaving enzymes than Bacteroidetes, and that, therefore, Bacteroidetes have higher efficiency in the degradability of fibre than Firmicutes. This implies that an increase in the Firmicutes to Bacteroidetes ratio in the luminal content resulting from high-grain feeding is undesirable.

High grain feeding and grain-induced SARA also affect the abundances of many members of the microbial community in the lumen content of the reticulo-rumen at the lower taxonomical levels. These effects include increasing the relative abundances of amylolytic and lactic acid utilising species, and reducing the relative abundances of fibrolytic species, with the magnitudes of these effects varying among studies and among cows within experiments (Khafipour et al., 2009b; Petri et al., 2013; Plaizier et al., 2017). These variations are, in part, due to host-microbiota coevolution throughout the course of life that results in co-differentiation or co-diversification of host-microbiota in an individualised manner (Zaneveld et al., 2008). These variations contribute to variability in the resilience of the microbiota and their hosts to changes in diet composition among cows. Nevertheless, some of the contradicting and inconsistent effects of 
dietary changes on gastrointestinal microbiota among studies may be also due to a large number of factors, such as variations in the inclusion rate and the type of grain, differences between experimental approaches, including those used for microbiota characterisation, such as DNA extraction methodology, standardisation of amount of DNA for sequencing, and the choice of primers used (universal bacterial primers $v$. target-specific primers, or different choices of hypervariable regions of $16 \mathrm{~S}$ ribosomal RNA gene), and the sample sizes among these studies (Khafipour et al., 2016).

\section{Differences between microbiota in the reticulo-rumen and the hind gut}

The presence of mucus in the hindgut and differences in the profile of dietary and mucosa-associated glycans between the hindgut and the rumen may contribute to differences in the abundances of bacteria taxa between these sites (Koropatkin et al., 2012). In the reticulo-rumen, most dietary glycans are exposed to fermentation and converted into VFA. Thus, the contribution of dietary glycans in shaping the microbiota composition of the hindgut is minor (Koropatkin et al., 2012). However, some members of the hindgut microbiota have the ability to degrade the glycans found in host mucous secretions or shed epithelial cells (Koropatkin et al., 2012). Hindgut microbiota vary widely in their glycan preferences as well as the number of different glycans that they are capable to degrade (Koropatkin et al., 2012). As such, species that are adapted to using these endogenous glycans, such as Bacteroides spp. that can degrade dozen different types of glycans (Johansson et al., 2011), can more effectively colonise hindgut mucosa, and thus, exert a disproportionate effect on the hindgut homoeostasis. As described in the 'Hindgut fermentation' section, highgrain feeding also affects the environmental conditions and the composition of the digesta in the hindgut, including increased starch fermentation and, as a result, the composition and functionality of the hindgut microbiota, similarly to what is observed in the rumen. This may contribute to the relatively high abundance of Firmicutes and the relatively low abundance of Bacteroidetes in the hindgut compared with the reticulo-rumen (Plaizier et al., 2017). These shifts can also pave the way for the enrichment of facultative pathogens that are a threat for food borne diseases in humans (Steele et al., 2016).

\section{Conclusions}

At the phylum and genus level, gastrointestinal microbiota are robust, but excessive grain feeding reduces the functionality of gastrointestinal microbiota by lowering their richness and diversity, reducing of the abundances of beneficial microbial taxa, and increasing the abundances of less beneficial and pathogenic microbial taxa, especially at the lower taxonomic levels. This needs to be confirmed by metagenomics and metatranscriptomics, as many microbial taxa share genes and functionality, and changes in the composition of the microbiota, therefore, do not have to indicate changes in their functionality.

\section{The role of the rumen and hindgut epithelia in gastrointestinal health}

Functional organisation of the gastrointestinal tract and its contribution to gastrointestinal health

The gastrointestinal tract must facilitate digesta passage, nutrient digestion, nutrient absorption, barrier function, luminal nutrient sensing and host-microbial communication. The regulation of these functions is complex, but all these functions are essential for balanced gastrointestinal tract function. In order to maintain homoeostasis in the presence of dense microbial biomasses in its lumen, the digestive tract has adopted strategies to physically limit the direct contact of microbiota in the digesta with the intestinal epithelium via mucosal layers. The rumen is an exception to this, as its epithelium does not contain a mucosal layer. Nevertheless, rumen epithelium has developed a multilayer structure with tight junctions to overcome this problem (Graham and Simmons, 2005). The epithelium of the hindgut does not have a multilayer structure, but it is covered by mucus, the inner layer of which is firmly attached to the epithelial cells and usually resistant to bacterial colonisation. These, and other differences in volume, retention time, mechanisms facilitating nutrient digestion (microbial fermentation $v$. mammalian enzymes), nutrient absorption, morphology and histology, and immune responsiveness among regions of the gastrointestinal tract are essential to understand when considering gastrointestinal health.

Volatile fatty acid absorption is critical as it supplies the vast majority of metabolisable energy and glucose to ruminants. Absorption of VFA also contributes to the stabilisation of ruminal pH (Penner et al., 2009; Aschenbach et al., 2011). The primary pathways allowing for improved stabilisation of ruminal $\mathrm{pH}$ is suspected to be the AE pathway, where VFA in the dissociated state are absorbed in exchange for the secretion of bicarbonate (Aschenbach et al., 2009). Subsequently, it has been shown that increasing the bicarbonate gradient increases the rate of VFA transport through the $A E$ pathway (Dengler et al., 2013). The contribution of VFA absorption towards stabilisation of ruminal $\mathrm{pH}$ suggests that increasing fermentation should result in a corresponding increase in VFA absorption. However, inducing SARA has been shown to reduce VFA absorption across the reticulorumen, while simultaneously increasing saliva production (Schwaiger et al., 2013a and 2013b). The reduction in VFA absorption as a consequence of SARA is likely a mechanism to prevent intracellular acidification and tissue damage associated with excessive absorption of VFA while partitioning bicarbonate through saliva to buffer ruminal $\mathrm{pH}$. The mechanisms regulating VFA absorption and partitioning arterial bicarbonate supply have not yet been elucidated. Other models to induce SARA, such as a rapid but moderate grain adaptation, have shown that the epithelium responds 
rapidly to increasing VFA concentrations. Mechanisms for how the ruminal epithelium responds have previously been discussed, but it is notable to indicate that much of the adaptive response occurs within 1 week of an abrupt diet change (Schurmann et al., 2014). The increase in absorption, however, does also coincide with a 'leaky' epithelium. In fact, Schurmann et al. (2014) reported increased rates of ${ }^{3} \mathrm{H}$-mannitol flux across the rumen epithelium with advancing days on a diet containing $50 \%$ concentrate. This increased permeability of the tissue may suggest that rapid dietary changes that should stimulate proliferation may also lead to increased permeability of the rumen epithelium. The same study also demonstrated that along with changes for ruminal fermentation and ruminal epithelial function, dramatic changes were observed in terms of digesta mass and tissue mass along the gastrointestinal tract (Gorka et al., 2017). Thus, studies evaluating the functionality of the gastrointestinal tract need to consider regions beyond the reticulo-rumen.

The mechanism(s) of translocation for toxic compounds may be favoured by impairment of the barrier function of the rumen epithelium (Emmanuel et al., 2007), depletion of protective factors (Hollmann et al., 2013) and increased luminal osmolality (Owens et al., 1998). Also, the chronic exposure to ethanol can increase the epithelial permeability and portal vein translocation of endotoxin (Enomoto et al., 2001). Interestingly, both concentrations of both endotoxin and ethanol in the reticulo-rumen fluid increased when amounts of grain in the diet of cows also increased (Ametaj et al., 2010). This indicates potential interactions of the generated compounds, that is, ethanol, biogenic amines and endotoxin, that potentiate the epithelial permeability of the endotoxin.

Although the reticulo-rumen has been the focus when investigating SARA, it is clear that outcomes arising from SARA affect multiple regions of the gastrointestinal tract. The organisation of the gastrointestinal tract also differs markedly with the reticulo-rumen and omasum consisting of a stratified squamous epithelium and the more distal regions containing simple epithelia. For the reticulo-rumen and the omasum, the stratified nature is thought to provide physical protection from abrasive feeds (Greenwood et al., 1997), while also supporting barrier function properties.

Past research has reported that the induction of acute ruminal acidosis decreases the barrier function of the total gastrointestinal tract (Minuti et al., 2014). However, that research was unable to determine regional effects and confirm whether the reticulo-rumen, hindgut regions, or other regions are likely to lead ruminants to greater risk for antigen or pathogen translocation. Although regional effects are rarely provided, Penner et al. (2014) has characterised the permeability of the gastrointestinal tract epithelia to small $\left({ }^{3} \mathrm{H}\right.$-mannitol) and large $\left({ }^{14} \mathrm{C}\right.$-inulin) molecules using the Ussing chamber approach. In this study, epithelia from the rumen, omasum, duodenum, jejunum, ileum, caecum, proximal colon and distal colon were collected from Holstein steers fed a forage-based diet. They reported that potentials for inulin to cross the epithelia of the rumen and omasum were high, despite having low permeability to mannitol. The jejunum was also noted as a region with a high permeability. Although these calves were not exposed to a nutritional challenge and therefore, the results should represent a 'healthy' gastrointestinal tract, they do suggest that the rumen may be implicated in the transepithelial flux of large molecules. Pederzolli et al. (2018) followed a similar model but induced ruminal acidosis to assess regional effects on epithelial barrier function resulting from ruminal acidosis. Surprisingly, they were not able to detect major changes in barrier function among regions of the gastrointestinal tract when compared with calves that were not challenged. Thus, the impact of ruminal acidosis on regional differences in epithelial barrier function remains not fully understood. However, from the literature reviewed here, it is evident that the translocation of large molecules such as lipopolysaccharide (LPS) can occur across the digestive tract and that high grain feeding increases this translocation. It cannot be assumed that this translocation occurs only in the rumen.

Although SARA has been a major focus as a causative factor negatively affecting gastro-intestinal health, it should be acknowledged that other factors such as low feed intake or rapid dietary transitions can also compromise the absorptive and barrier function of the gastrointestinal tract. For example, Zhang et al. (2013a and 2013b) restricted heifers to $75 \%, 50 \%$ or $25 \%$ of their ad libitum dry matter intake and observed a dose-dependent reduction in absorption of VFA across the reticulo-rumen along with an increase in permeability of the total gastrointestinal tract when restricted to $25 \%$ of their ad libitum feed intake. Although the magnitude of low feed intake may seem extreme, transition dairy cattle, particularly those experiencing transition diseases (hypocalcaemia, ketosis) or infectious diseases (metritis, mastitis), may have dry matter intake reductions of a similar extent. In another study, evaluating milk-fed Holstein calves, Wood et al. (2015) reported an age-dependent decrease in the permeability of the total gastrointestinal tract. However, this age-dependent reduction was disrupted by weaning with weaned calves having markedly greater permeability than calves that were not weaned. Thus, in addition to ruminal acidosis, factors that reduce or dramatic change nutrient supply, including nutrient supply to the gastrointestinal tract, can also compromise the functionality of this tract.

\section{Genomic alterations and implications on health: rumen epithelium and beyond}

The advent of high-throughput gene expression tools, such as microarrays, for use in cattle (Everts et al., 2005) have been instrumental for the study of gastrointestinal health as it relates to ruminal acidosis and its peripheral tissue responses. Steele et al. (2011a) reported a comprehensive analysis of the rumen epithelium transcriptome in cows afflicted by ruminal acidosis upon feeding a $65 \%$ grain diet. The study identified several genes associated with cholesterol synthesis as being markedly downregulated after a 3- 
week induction of ruminal acidosis. This data indicated that, besides the well-described damage of the epithelial morphology during acidosis, an alteration in cholesterol metabolism contributes to malfunction of these cells, for example, through an aberrant cell membrane lipid composition. This malfunction could have a negative impact on transport mechanisms (Christon et al., 1991). In non-ruminant models, the metabolism of cholesterol to isoprenoid intermediates also induces changes in cellular proliferation, migration and oxidative stress, all of which are associated with grain feeding (Gabel et al., 2002).

Steele et al. (2011a) also recognised that IGF binding proteins (IGFBP3, 5 and 6) and the cadherin-like transmembrane glycoprotein desmoglein 1 (DSG1), all with a potential role in rumen papillae proliferation (Shen et al., 2004), were altered during rumen acidosis. For instance, downregulation of DSG1 was associated with increased permeability or paracellular transport, thereby providing the means for microbes, LPS and other toxic compounds (e.g. bioactive amines) to translocate and elicit detrimental health effects (Steele et al., 2011b and 2012). The gradual upregulation of IGFBP5 coupled with a gradual downregulation of IGFBP3 during adaptation to a high-grain diet have been consistent in studies of ruminal acidosis. These effects provide a link between IGF-1 and ruminal cell proliferation (Shen et al., 2004), that is, an upregulation of IGFBP5 potentiates the effect of IGF-1 on cell proliferation, whereas downregulation of IGFBP3 encourages cell growth (Steele et al., 2012). It is noteworthy that the changes in DSG1, IGFBP5 and IGFBP3 expression in response to chronic acidosis also have been detected in rumen epithelium tissue postpartum compared with prepartum (Steele et al., 2015). This leads to the suggestion that the IGF-axis may be involved in the adaptation of the rumen epithelium to the higher fermentable diets typical of the postpartum period.

Functional genomics approaches, either utilising microarrays or Reverse transcription polymerase chain reaction (RT-PCR), have also verified differential expression of genes with roles in maintenance of intracellular $\mathrm{pH}(\downarrow$ solute carrier family 9 member A3 (SLC9A3); Schlau et al., 2012), cholesterol synthesis ( $\downarrow$ 3-hydroxy-3-methylglutaryl-CoA synthase (HMGCS) 1; $\downarrow$ lanosterol synthase; Gao and Oba, 2016), or lack of change in ketogenic genes known to be controlled at the level of transcription (e.g. HMGCS2; 3-hydroxymethyl-3methylglutaryl-CoA lyase; Steele et al., 2011; Schlau et al., 2012; Gao and Oba, 2016). Some of these effects have been verified at the protein level (e.g. $\downarrow$ solute carrier family 16 member 1), whereas others have been opposite (e.g. $\uparrow$ SLC9A3) (Laarman et al., 2016). Clearly, it cannot be assumed that transcription controls the activity of enzymes or transporters involved in the key function of the ruminal epithelium, and care should be taken when interpreting such findings. However, besides allowing for a holistic evaluation of physiologic responses, genome-enabled technologies provide the means to generate novel hypotheses than can be tested in a more discrete fashion. An example of this is a recent in vitro work in which isolated rumen epithelial cells were cultured in vitro with two levels of $\mathrm{pH}$ (7.4 or 5.5) and two concentrations of LPS (0 or $10 \mu \mathrm{g} / \mathrm{ml}$ ) (Zhang et al., 2016). Results clearly underscored the positive association between LPS and pro-inflammatory markers in rumen epithelium (e.g. interleukin (IL)-1 $\beta$, chemokines), and the negative association between $\mathrm{pH}$ and pro-inflammatory markers.

Beyond the well-established effects of ruminal acidosis on epithelial integrity and molecular responses, there has been interest in using genome-enabled technologies for evaluating the post-ruminal effect of acidosis. Examples include work with mRNA and/or protein expression in the liver (Chang et al., 2015; Xu et al., 2017), white blood cells (Stefanska et al., 2017) and mammary gland (Jin et al., 2016; Zhang et al., 2016). In regards to the liver, acute (1 day) or chronic (10 weeks) ruminal acidosis in Holstein cows induced by feeding a high-grain diet causes upregulation of inflammatory mediators (Chang et al., 2015; Xu et al., 2017). Hence, the pro-inflammatory response to acidosis is not unique to rumen epithelium and even extends to circulating white blood cells (Stefanska et al., 2017) and the mammary gland (Zhang et al., 2016). These molecular responses across studies are often accompanied by reductions in rumen $\mathrm{pH}$ and increases in concentrations of rumen LPS, along with classical decreases in the ratio of rumen fluid acetate to propionate.

Recent efforts to better understand the response of the liver to grain challenges have gone beyond the inflammatory response. For instance, an acute grain challenge after a 1 day of feed restriction downregulated genes encoding metabolic enzymes associated with elongation (ELOVL fatty acid elongase 6) and desaturation (stearoyl-CoA desaturase) of long-chain fatty acids but upregulated gluconeogenic genes (pyruvate dehydrogenase kinase 4; phosphoenolpyruvate carboxykinase 1; Xu et al., 2017). From a mechanistic standpoint, blocking elongation and desaturation could lead to ceramide production and trigger inflammation (Kasumov et al., 2015). Upregulation of fatty acid oxidation and gluconeogenic genes coincided with an increase in plasma free fatty acids, suggesting transient adaptations in energy metabolism. At least in non-ruminants, these enzymes are known to be regulated at the transcriptional level (Nakamura et al., 2014) suggesting that changes observed could have functional relevance in terms of liver function. It is uncertain if these metabolic responses occur during long-term ruminal acidosis.

Although research to date has clearly linked ruminal events to molecular alterations in various tissues, the actual mechanisms behind the changes in transcription and translation during ruminal acidosis are not well known. As demonstrated by a recent study evaluating epigenetic mechanisms associated with ruminal acidosis (Chang et al., 2015), this represents a fertile area for future research. The focus on epigenetic regulation during ruminal acidosis arose from data in model organisms demonstrating that excessive activation of inflammatory pathways induces endotoxin tolerance and cross-tolerance towards other pathogen-associated molecular patterns (Foster et al., 2007; 
Saturnino et al., 2010). Chang et al. (2015) demonstrated that high-grain induced ruminal acidosis for 10 weeks not only upregulated expression of Toll-like receptor 4 (TLR4) mRNA and protein, but that this effect was associated with TLR4 promoter hypomethylation and lower chromatin compaction, all of which suggested a functional link between LPS translocation from rumen to liver causing inhibition of DNA methylation rendering the DNA of inflammatory genes more accessible to the action of transcription factors such as NF- $\kappa B$ (Chang et al., 2015).

\section{Gastrointestinal health and inflammation}

Many studies have associated SARA with inflammation (Kleen et al., 2003; Enemark, 2008; Plaizier et al., 2008). The inflammation could be located in the rumen epithelium (rumenitis) or be systemic. The systemic inflammation could result from the translocation of endotoxins such as LPS and/ or other immunogenic compounds out of the digestive tract (Plaizier et al., 2012b; Figure 1). Rumenitis may result from parakeratosis the rumen epithelium due to the increases of the acidity and LPS content of rumen digesta (Kleen et al., 2003; Enemark, 2008; Plaizier et al., 2008). This may reduce absorption, but may also reduce the barrier function, of the rumen epithelium (Emmanuel et al., 2007; Plaizier et al., 2008 and 2012b, see also the 'The role of the rumen and hindgut epithelia in gastrointestinal health' section). In support of this, Steele et al. (2009) showed that a transition from a $100 \%$ forage diet to a $79 \%$ grain diet compromised the rumen epithelium through sloughing of the stratum corneum and reductions of cell adhesions in other strata. The increase in grain feeding and the resulting reduction in the rumen $\mathrm{pH}$ in this study were much greater than those of the SARA induction studies summarised in the Supplementary Material S2. Hence, it is unlikely that these SARA inductions resulted in the acute lactic acidosis and severe parakeratosis and rumenitis observed by Steele et al. (2009). Despite this, Dionissopoulos et al. (2012) observed that grain-induced SARA affected the functionality of the rumen epithelium and that the immune system was involved in the adaptation of this epithelium to high-grain feeding.

It has also been proposed that the inflammation during SARA is caused by translocation of immunogenic bacterial endotoxins, such as LPS, from the digestive tract (Figure 1; Mullenax et al.,1966; Nagaraja et al., 1978b). This endotoxin is a component of the outer wall of Gram-negative bacteria. During rapid growth or lysis of bacteria, LPS is released from the cell wall, and its toxic component is exposed (Hurley, 1995; Wells and Russell, 1996). Hence, free LPS, but not LPS in intact bacteria is immunogenic (Plaizier et al., 2012b).

Most studies in the Supplementary Material S2 agree that high grain feeding and the resulting SARA increase the concentration of free LPS in rumen digesta. However, the concentrations of this LPS during SARA varied greatly among these studies, that is, from 28851 endotoxin units $(E U) / \mathrm{ml}$ (Dionissopoulos et al., 2012) to $145000 \mathrm{EU} / \mathrm{ml}$ (Khafipour et al., 2009b). The rumen LPS concentrations during the control treatment also varied greatly among these studies. Studies also varied the assay used for the measurement of LPS and in the processing of samples, which implies that absolute LPS concentrations are difficult to compare among experiments. In contrast to grain-induced SARA, inductions of SARA by feeding pellets of ground forage, and, thereby, reducing the peNDF intake, resulted in no or only a very limited increase in free LPS in rumen digesta (Khafipour et al., 2009b; Li et al., 2012b). Plaizier et al. (2014) showed that in increases in grain feeding result in prolonged rises of rumen LPS, which suggests that shedding of LPS by growing bacteria also contribute to the free LPS pool in the reticulo-rumen.

Bertok (1998) described LPS is degraded in the small intestine. This is supported by the observation of Plaizier et al. (2014) that increased grain feeding raised the concentration of free LPS in the rumen, caecum, but not in the duodenum and jejunum. This suggests that LPS in the large intestine must originate in this part of the digestive tract.

Li et al. (2012a, 2012b and 2016) and Qumar et al. (2017) also observed that grain-induced SARA challenges increased the free LPS content of digesta in the large intestine and faeces. This is likely the result of hindgut acidosis caused by increases in the amount of dietary starch that bypasses reticulo-rumen fermentation and digestion in the small intestine (Gressley et al., 2011). Due to differences in their anatomical structure, the barrier function of the monolayer epithelium of the large intestine for LPS may be compromised easier than that of the multilayer rumen epithelium (Emmanuel et al., 2007; Plaizier et al., 2012b). High LPS in the large intestine may, therefore, be a larger health risk than high LPS in the reticulo-rumen.

Liver cells, including hepatic and Kupffer cells, breakdown LPS, which is subsequently excreted (Tomlinson and Blikslager, 2004; Satoh et al., 2008). This implies that when LPS is detectable in peripheral blood, the LPS clearing capacity of the liver has been exceeded. Hence, a malfunctioning of the liver, such as that often seen in early lactation, could aggravate the LPS-related symptoms of SARA. The effects of SARA challenges on the concentration of LPS in blood plasma, therefore, vary greatly among studies, as in the studies of Supplementary Material S2, LPS was only detected in blood plasma by Chang et al. (2015), Bilal et al. (2016) and Li et al. (2016), which shows that LPS can translocate out of the digestive tract. The discrepancies among studies may be due to differences in the duration and severity of the SARA challenge, and thresholds below which LPS does not translocate. Differences in sample processing and the lymulus amoebocyte lysate (LAL) test among studies may also contribute to these discrepancies.

Plaizier et al. (2014) did not detect LPS in blood plasma in calves on a moderate grain diet. The LPS concentration and acidity of rumen and hindgut digesta in that study were lower than those in the studies that observed increases in blood LPS, suggesting that thresholds for these measures exist below which enteral LPS does not translocate or the translocated LPS is degraded in the liver. 


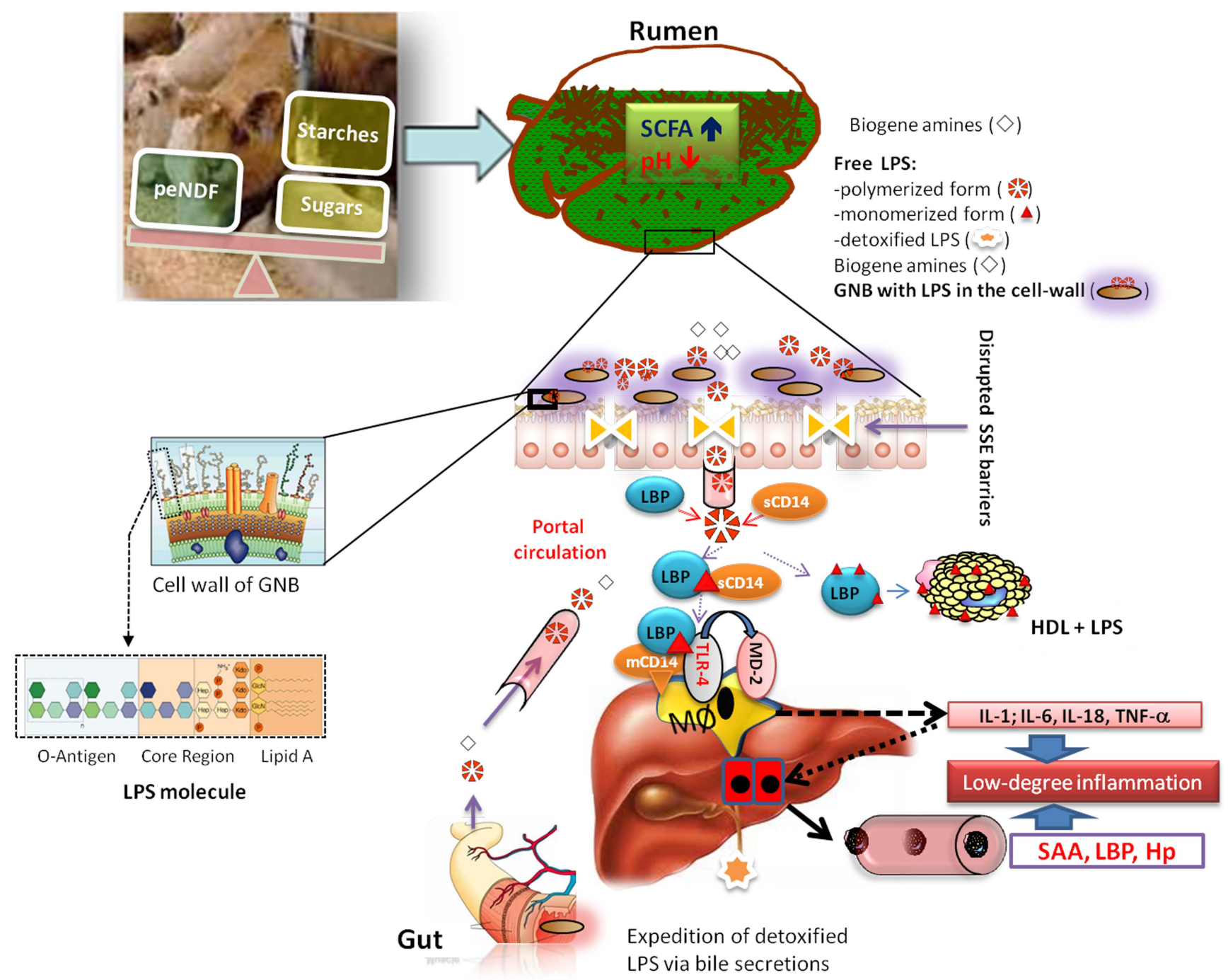

Figure 1 Proposed mechanisms through which high grain feeding causes inflammation in dairy cows, and the role of lipopolysaccharide (LPS) endotoxin in these mechanisms. $\mathrm{GNB}=$ gram-negative bacteria; $\mathrm{HDL}=$ high-density lipoprotein; $\mathrm{Hp}=$ haptoglobin; $\mathrm{IL}=$ interleukin; $\mathrm{LBP}=\mathrm{LPS}$ binding protein; mCD14 = membrane CD14; MD-2 = Lymphocyte antigen 96; peNDF = physically effective NDF; SAA = serum amyloid $A ; s C D 14=$ soluble $C D$ 14; SCFA = short-chain fatty acids; SSE = simple sequence editor; TLR = Toll-like receptor; IL = interleukin; TNF $\alpha=$ tumour necrosis factor $\alpha$.

For LPS to cause an immune response, it must combine with LPS binding protein (LBP) and the resulting complex must bind to CD14, TLR-4, MD2 receptors (Figure 1; Netea et al., 2002; Tomlinson and Blikslager, 2004). These receptors are located on a variety of blood cells, including monocytes, macrophages, dendritic cells, and B cells, and on the intestinal epithelium and the liver (Netea et al., 2002; Tomlinson and Blikslager, 2004; Zebeli and Metzler-Zebeli, 2012). The binding of LPS-LBP to its receptors is assumed to promote the secretion of pro-inflammatory cytokines, such as tumor necrosis factor (TNF)- $\alpha, \mathrm{IL}-1$ and IL-6. (Figure 1; Tomlinson and Blikslager, 2004), and these cytokines are expected to initiate the synthesis of serum amyloid $A(S A A)$ and haptoglobin (Hp) in the liver (Figure 1). Some studies have indeed shown that grain-induced SARA increased the concentrations of TNF- $\alpha$, IL-1 $\beta$ and IL- 6 in peripheral blood plasma of cows (Bilal et al., 2016; Guo et al., 2017) and goats (Chang et al., 2015). However, Li et al. (2016), observed that, despite increases in SAA, Hp and LBP, grain-induced SARA reduced the blood plasma concentration of IL- 6 , and did not affect that of TNF- $\alpha$. The discrepancies among these studies may, in part, be explained by differences in methodologies, including the assays of cytokines. However, the relationships between grain-induced SARA, cytokines and acute phase proteins is not yet well understood.

Most studies agree that grain-induced SARA causes an acute phase response characterised by increases in the blood plasma concentrations of acute phase proteins, such as SAA, Hp and LBP (Figure 1; Supplementary Material S2, Baumann and Gauldie, 1994; Tomlinson and Blikslager, 2004; Plaizier et al., 2012b). In contrast, inducing SARA by feeding pellets of ground alfalfa did not increase these concentrations (Khafipour et al., 2009b; Li et al., 2012b). The SAA and Hp proteins are not specific to LPS from the gut, and their concentrations are also increased during inflammations such as mastitis and metritis (Baumann and Gauldie, 1994). The concentrations of the acute proteins during grain-induced 
SARA in the studies summarised in the Supplementary Material S2 are in the high end of normal, or just above the normal range (Humblet et al., 2006). Intravenous administration of 100 and $1000 \mathrm{ng} / \mathrm{kg}$ of Escherichia coli LPS to cows has resulted in increases in SAA and Hp that were at least 10 times higher than those reported during grain-induced SARA studies of the Supplementary Material S2 (Jacobsen et al., 2004). Also, in contract with these SARA studies, the intravenous administration of LPS was followed by fever, reduced rumen motility and leukopenia followed by leukocytosis (Jacobsen et al., 2004). These clinical symptoms have not been observed during grain-induced SARA studies (Gozho et al., 2007; Li et al., 2012b; Danscher et al., 2015).

The discrepancy between the administration of LPS and the grain-induced SARA with regards to the resulting inflammation could be related to the source of the LPS and the duration of the exposure to this LPS. Jacobsen et al. (2004) administered $E$. coli LPS to cows. This may not be fully representative for the translocation of LPS from the reticulorumen, as $E$. coli is not a common gram-negative bacteria in the rumen (Khafipour et al., 2009c). Gram-negative bacteria vary in the toxicity of their LPS, which may be related to differences in its three-dimensional shape (Netea et al., 2002). It has been suggested that the conical-shaped LPS, such as that of $E$. coli, is more toxic than the cylindrically and intermediately shaped LPS, such as that of most gramnegative bacteria in the digestive tract of cows (Netea et al., 2002). Escherichia coli LPS is more toxic than the LPS of these more common gram-negative rumen bacteria (Netea et al., 2002). Hence, intravenous administration of $E$. coli LPS may result is a more severe immune response than intravenous administration of LPS of common gram-negative rumen bacteria, such as Prevotella spp. Another difference between infection by gram-negative bacteria and grain-based SARA is that in the case of these infections the exposure to LPS is high, but short term, whereas this exposure during SARA may be lower and chronic (Andersen, 2003; Gott et al., 2015). Repeated and chronic exposure to LPS can result in endotoxin tolerance (Andersen, 2003). The mechanisms responsible for this tolerance are not yet well understood (Andersen, 2003). It has been suggested that endotoxin is part of a regulation mechanism for inflammation that prevents excessive effects and costs of inflammation that exceed its benefits. When this tolerance is achieved, responses of the animals, including an immune response, are either limited or absent. This was illustrated by Gott et al. (2015), who observed that grain-induced SARA, which was assumed to increase the LPS concentration in blood, reduced the increases in SAA in milk resulting from an intra-mammary challenge of $E$. coli LPS.

Translocation of LPS into the blood circulation does not have to be the sole cause of inflammation, as when a reduced barrier function of gastrointestinal epithelia causes the translocation of LPS, other immunogenic compounds, such as bioamines, may translocate also (Figure 1). Oxidative stress can also lead to inflammation in cows (Sordillo and Aitken, 2009). Karmin et al. (2011) concluded that a grain- based SARA challenge resulted in oxidative stress, as this challenge increased the degree of lipid peroxidation as indicated by an increase in blood plasma levels of malondialdehyde from 2.63 to $11.18 \mathrm{nmol} / \mathrm{l}$ at $6 \mathrm{~h}$ after feed delivery. Hence, oxidative stress may also contribute to the systemic inflammation observed during grain-induced SARA.

\section{Rumen modifiers to decrease the risk of ruminal acidosis}

As an adjunct to balanced diets, the risk of rumen acidosis can be reduced by the inclusion of rumen modifiers that include antibiotics, buffers and neutralising agents, yeasts, direct-fed microbials and enzymes, and, possibly, by essential oils (Khorrami et al., 2015; Malekkhahi et al., 2015).

Rumen modifiers appear to influence the reticulo-rumen by different mechanisms, but our understanding of these mechanisms is largely based on in vitro ruminal responses and may not reflect in vivo responses. Animal to animal variation in the response to these compounds suggests that no single feed additive will be capable of controlling ruminal acidosis in all cattle under all circumstances (Golder et al., 2014a). Different feed additives may need to be used depending on the composition of the diet. Further work is required to elucidate these mechanisms, particularly during different feeding situations.

\section{Buffers}

Buffers are commonly included in dairy cow diets to stabilise the rumen pH (Golder, 2014). Sodium bicarbonate and magnesium oxide are commonly used rumen buffers (Staples and Lough, 1989; Hu and Murphy, 2005; Golder, 2014). In addition to buffering, sodium bicarbonate also stabilises the rumen acidity by increasing the water intake and reducing ruminal starch digestion (Russell and Chow, 1993). Erdman (1988) observed that adding a combination of magnesium oxide and bicarbonate to dairy cow diets increased butter fat by $0.3 \%$ to $0.4 \%$. Also, Golder et al. (2014b) observed that adding both sodium bicarbonate and magnesium oxide to the diet reduced the variability in feed intake during a carbohydrate challenge study. Hence, the effects of these buffers appears to be additive. Other buffers that have been added to cattle diets include potassium carbonate, potassium bicarbonate, and sodium sesquicarbonate and the skeletal remains of the seaweed Lithothamnium calcareum (Erdman, 1988; Golder, 2014; Lean et al., 2014). In addition to buffering, supplementing with sodium bicarbonate, potassium carbonate, potassium bicarbonate and sodium sesquicarbonate affects the dietary cation-anion difference.

\section{Antimicrobials \\ Countries differ greatly in the availability of antimicrobial agents for use in acidosis control, and it is likely that less of these antibiotics will be available in the future due to con- cerns related to antibiotic resistance. Also, it should not be assumed that other products used to control bacterial}


populations will not be associated with antimicrobial resistance (Nagaraja and Taylor, 1987). Antibiotics that are used in the cattle industries include tylosin and virginiamycin (VM). Feeding combinations of feed additives may have synergistic effects (Nagaraja et al., 1987; Lean et al., 2000; Golder et al., 2014b), but literature is limited, and further research is required in this field. The latter statement extends beyond the interactions between ionophores and antibiotics to the vast combination of rumen modifying agents that are used in dairy herds and feed lots. These combinations include buffering agents, ionophores, bambermycin, yeasts, yeast products and direct fed microbials (DFM).

Tylosin is a macrolide antibiotic that inhibits protein biosynthesis in Gram-positive bacteria. Its main use is to reduce the incidence of the liver abscess in feedlot cattle that are associated with rumen acidosis (Amachawadi and Nagaraja, 2016). Tylosin increased total VFA and butyrate concentrations and tended to decrease plasma lactate concentrations in the reticulo-rumen of lactating dairy cattle during a ruminal acidosis challenge (Lean et al., 2000). However, tylosin did not affect VFA and lactate in the rumen in steers (Horton and Nicholson, 1980; Nagaraja et al., 1999). Despite the more than 45 years of use, Amachawadi and Nagaraja (2016) found no evidence of resistance to tylosin in Fusobacterium necrophorum and Trueperella pyogenes isolates from liver abscesses of cattle.

Virginiamycin is another antibiotic that is effective against gram-positive bacteria that are associated with lactic acid production. It has been used successfully in feedlots to reduce the risk of lactic acidosis (Rowe and Pethick, 1994; Rogers et al., 1995). It has also been observed that VM stabilises rumen $\mathrm{pH}$ and increases the digestibility of and energy utilisation from grain (Godfrey et al., 1995). Another effect of VM is that can increase propionate production in the reticulorumen (Nagaraja et al., 1995a and 1995b; Clayton et al., 1996).

Classes of antibiotics that are not used in human medicine, and, therefore, may have more potential for use in livestock include the ionophores and bambermycin. Monensin is a carboxylic polyether ionophore produced by a naturally occurring strain of Streptomyces cinnamonensis (Haney and Hoehn, 1967). It is approved for use in lactating cattle in several countries including: Australia, the United Kingdom, Argentina, Brazil, New Zealand, South Africa, Canada, and the United States. Sodium monensin use increases ruminal propionate production, reflecting an increase in propionate producing bacteria compared with those producing formate, acetate, lactate and butyrate (Lean et al., 2014). Methane production from the reticulo-rumen is decreased and dietary proteins are less digested in the reticulo-rumen (Richardson et al., 1976; Russell and Houlihan, 2003). Monensin selectively inhibits gram-positive bacteria, in particular lactate producing bacteria in the rumen without affecting most lactate utilising bacteria (Dennis et al., 1981; Weimer et al., 2008). Consequently, monensin has been proposed as an agent for the control of rumen lactic acidosis. There are very few in vivo studies that provide information on ruminal lactate production or concentrations following monensin. Burrin and Britton (1986) found that ruminal lactate concentrations in feedlot steers were not affected by monensin. Nagaraja et al. (1981) found both increased and decreased lactate concentrations in the reticulo-rumen due to monensin treatment in three acidosis challenge studies. Nagaraja et al. (1982) observed that monensin decreased ruminal lactate in a subsequent glucose challenge study, but Golder (2014) did not find that monensin affected ruminal lactate in cattle. Fairfield et al. (2007) found that a monensin controlled release capsule did not affect rumen $\mathrm{pH}$ and lactate in dairy cows during the transition period and early lactation in which rumen acidosis was not common.

Bacteria, such as Streptococcus bovis may outgrow the amount of monensin administered to control microbial growth due to their high binding capacity for monensin (Chow and Russell, 1990). Hence, monensin may not stabilise the reticulo-rumen when it is subjected to conditions conducive to acute acidosis and the growth of $S$. bovis, such as feeding highly fermentable diets. As a result, in vitro studies on monensin that were conducted at near-neutral pH and at lower cell densities than in vivo may not be representative for the role of this ionophore in grain-fed cattle.

Guan et al. (2006) observed that monensin had a transitory effect on protozoal numbers and methane emissions, suggesting that the microbiota can adapt to ionophores and their effects may be reduced over time. Notwithstanding this, there is evidence of increased production of propionate from lactate, which is a ruminal adaptation that sequesters hydrogen ions in safer ruminal pools, when monensin is fed in diets that may cause rumen acidosis (Lunn et al., 2005). Hence, it is possible that monensin increases ruminal stability under conditions of moderate substrate loads. Monensin also appears to be effective in controlling acidosis risks when fed with tylosin or VM (Nagaraja et al., 1987; Lean et al., 2000; Golder et al., 2014b).

Lasalocid is a polyether antibiotic ionophore derived from strains of Streptomyces lasaliensis that has also been used to control lactic acidosis (Nagaraja et al., 1981). Lasalocid can translocate monovalent and divalent cations across bacterial cell membranes (Bergen and Bates, 1984), resulting in a modified reticulo-rumen environment through death or impaired growth of primarily Gram-positive rumen bacteria. The use of lasalocid equalled or exceeded the reduction in lactic acid production observed for monensin (Nagaraja et al., 1981), however, neither product influenced rumen $\mathrm{pH}$. Both monensin and lasalocid prevented acute lactic acidosis in the study of Nagaraja et al. (1981). Nagaraja et al. (1982) found that lasalocid levels between 0.33 and $1.30 \mathrm{ppm}$ reduced lactic acid concentrations and increased $\mathrm{pH}$ in the reticulo-rumen in cattle with glucose-induced lactic acidosis. Golder and Lean (2016) observed that lasalocid increased total VFA, propionate and ammonia and decreased acetate and butyrate molar percentage, without affecting the $\mathrm{pH}$ and the molar percentage of valerate in the reticulo-rumen.

Bambermycin is a phosphoglycolipid antibiotic that affects the functionality of rumen microbiota (Edwards et al., 2005). 
It is also referred to as flavomycin, flavophospholipol and moenomycin (Edwards et al., 2005; Golder, 2014). This antibiotic reduces lactic acid production in vitro Meissner et al. (2014), but does not appear to affect VFA production (Edwards et al., 2005). The effects of bambermycin on the production of dairy cows vary greatly among studies (Golder, 2014). Also, in a small beef cow study, bambermycin did not affect production, and rumen fermentation (Golder, 2014).

The effects of monensin and lasalocid on rumen VFA are not consistent among studies, not even among studies during which rumen acidosis was induced (Duffield et al., 2008; Golder, 2014; Golder and Lean, 2016). It is assumed that the variation in interactions between the host genome, ruminal meta-genome and the diet is partly responsible for the variation in response to antibiotics (Brulc et al., 2009; Jami and Mizrahi, 2012; Petri et al., 2013).

\section{Microbials}

A number of products of single or mixed bacterial cultures are used in cattle, including strains from Bifidobacterium, Enterococcus, Streptococcus, Prevotella, Bacillus, Lactobacillus, Megasphaera and Propionibacteria. Lactobacillus acidophilus and Propionibacterium freudenreichii are the primary bacterial DFM used in the dairy industry (Krehbiel et al., 2003; McAllister et al., 2011). Similar agents have been used in the beef industry.

Responses to DFM have been inconsistent, reflecting supplementation with many different organisms, strains of organisms, and combinations of organisms, differences in micro-organism inclusion level, diet, feeding management and animal factors (Krehbiel et al., 2003; McAllister et al., 2011). In general, there is evidence that DFM increased milk production in dairy cattle, improved health and performance in calves, and could reduce the risk of ruminal acidosis (Krehbiel et al., 2003). These responses reflect use of bacteria that utilise lactate, for example, Megasphera elsdenii (Klieve et al., 2003; Leeuw et al., 2009; Meissner et al., 2014) and Selenomonas ruminantium (Chiquette et al., 2015), or increase propionate production (Kenney et al., 2015; Vyas et al., 2015). Responses to DFM in the rumen include a decrease in the area below a ruminal $\mathrm{pH}$ threshold defined for SARA, an increase in propionate concentrations, increased protozoa counts, and altered counts of lactateutilising and lactate producing bacteria (Krehbiel et al., 2003; McAllister et al., 2011). Although there has been a very substantial amount of work on establishing mechanism and application of particular DFMs, including M. elsdenii, evidence of adoption is limited.

Yeasts are a non-homogenous group of rumen modifiers. Assumptions of equivalency of action in the reticulo-rumen or responses to supplementation within the group should, therefore, not be made. Most yeasts used in the livestock industry, contain, or are derived from Saccharomyces cerevisiae and Aspergillus oryzae strains, respectively (Yoon and Stern, 1995; Seo et al., 2010). There are two major types of yeast marketed; live yeast, sometimes termed 'active dry yeast', containing $>15$ billion live yeast cells/g; and yeast fermentation byproducts that do not contain live yeast but do include dead yeast, fermentation medium and various fermentation compounds. The action of the live yeast depends on the function of live yeast cells in the rerticulo-rumen, whereas the fermentation byproducts act through the supply of products of fermentation using yeasts.

Actions that have been identified with live yeasts include small increases in rumen $\mathrm{pH}$, reductions in lactic acid, enhanced fibre digestion and small increases in VFA production (Erasmus et al., 1992; Chaucheyras-Durand et al., 2008; Golder, 2014). These actions, are modest in magnitude but may synergise with other strategies to control the risk of acidosis. Interestingly, feeding a yeast $(S$. cerevisiae CNCM I-1077; Levucell SC20; Lallemand Animal Nutrition, Montreal, QC, Canada) and monensin modified eating behaviour in dairy heifers by increasing the time taken to eat, reducing DMI at feeding in an acidosis challenge study using starch and fructose (Golder et al., 2014b). Notwithstanding these changes, average daily gain (1.67 v. control $1.47 \mathrm{~kg} /$ day) and feed conversion ratio was high (6.44 v. 9.34 control kg of $\mathrm{DMI} / \mathrm{kg}$ of gain), but not significantly, altered in this group. DeVries and Chevaux (2014) found similar changes with the same yeast in lactating cows that increased meal frequency and decreased meal size and length of feeding bouts. Other actions of yeasts include increasing fibre digestion and increasing microbial protein production (Chaucheyras-Durand et al., 2008) may be significant factors that could reduce the risk of acidosis. There appears to be relatively little evidence that yeast culture products increase the rumen $\mathrm{pH}$ (Erasmus et al., 1992; Robinson, 1997; Lehloenya et al., 2008; Moya et al., 2009). However, Li et al. (2016) found that an $S$. cerevisiae fermentation product (Diamond V XPC; Diamond V Mills Inc., Cedar Rapids, IA, USA) stabilised rumen $\mathrm{pH}$ in dairy cows during moderate and high grain feeding.

\section{Conclusions}

The common practice of feeding high-grain diets to dairy cows can reduce gastrointestinal health by causing a rumen $\mathrm{pH}$ depression, inflammation, hindgut acidosis and oxidative stress, by increasing the endotoxin and pathogen contents of digesta, and by reducing the absorptive and barrier capacities of epithelia, functionality of gastrointestinal microbiota and nutrient utilisation. This reduced gastrointestinal health has been referred to as 'SARA', but many conflicting definitions of 'SARA' exist. As the causes of SARA are multifactorial, its diagnosis based solely on the rumen $\mathrm{pH}$ is not accurate. A combination of measures, including rumen $\mathrm{pH}$, milk fat content, milk fatty acid profile, rumen motility, chewing behaviour, sorting, faeces consistency and lameness of cows, as well as chemical, physical, and digestibility analyses of the diet, and an assessment of bunk and other feeding management will be required for an accurate analysis. 
The normal functioning of the gastrointestinal ecosystem requires a proper balance of dietary nutrients, and especially of rapidly degradable carbohydrates, such as starch and peNDF. A number of feed supplements, including buffers, antibiotics, probiotics, DFM and yeast products are available to enhance the gastrointestinal health of high-grain fed cows. However, their effects vary among studies, and their mechanisms of actions are not always sufficiently understood. The use of some of these products, such as antibiotics, may have to be phased out.

Excessive grain feeding alters the abundances of beneficial, less beneficial and pathogens microbial taxa in the digestive tract, especially at the lower taxonomic levels. This may reduce the functionality of these microbiota, but this needs to be confirmed by metagenomics and metatranscriptomics. Excessive grain feeding also increases the shedding of endotoxins, including LPS, by gram-negative bacteria. Translocation of endotoxins out of the digestive tract may cause systemic inflammation. The impact of this translocation is not yet well understood, as the toxicity of these translocated endotoxins has not yet been determined, and prolonged systemic exposure to these endotoxins may result in endotoxin tolerance. Translocation of other immunogenic compounds may also contribute to this inflammation. Metabolomics analysis of rumen fluid and gastrointestinal permeability data have revealed pathways whereby toxic molecules produced during acidosis can induce local inflammatory and metabolic responses in organs such as the liver and mammary gland, but also immune cells in the circulation. There is clearly a regulation of tissue function at the level of mRNA and protein, including some control transcription and translation stemming from epigenetic mechanisms.

\section{Supplementary material}

To view supplementary material for this article, please visit https://doi.org/10.1017/S1751731118001921

\section{Acknowledgements}

The authors thank the organisers of the 10th International Symposium on the Nutrition of Herbivores for their invitation to present at this symposium and publish this review. Students, technical staff and research staff at the institutions of all authors are thanked for their contributions to the reviewed research. Thanks also go out to the numerous funding agencies that supported this research.

\section{Declaration of interest}

Authors declare no conflict of interest and nor competing interest.

\section{Ethics statement}

Not applicable.
Software and data repository resources

None of the data were deposited in an official repository.

\section{References}

Albenberg L, Esipova TV, Judge CP, Bittinger K, Chen J, Laughlin S, Grunberg S, Baldassano RN, Lewis JD and Li H 2014. Correlation between intraluminal oxygen gradient and radial partitioning of intestinal microbiota. Gastroenterology 147, 1055-1063.e1058.

Amachawadi RG and Nagaraja TG 2016. Liver abscesses in cattle: a review of incidence in holsteins and of bacteriology and vaccine approaches to control in feedlot cattle. Journal of Animal Science 94, 1620-1632.

Ametaj BN, Zebeli Q, Saleem F, Psychogios N, Lewis MJ, Dunn SM, Xia J and Wishart DS 2010. Metabolomics reveals unhealthy alterations in rumen metabolism with increased proportion of cereal grain in the diet of dairy cows. Metabolomics 6, 583-594.

Andersen PH 2003. Bovine endotoxicosis - some aspects of relevance to production diseases. A review. Acta Veterinaria Scandinavica 98, 141-155.

Anele U, Refat B, Swift M-L, Zhao Y, Doublier C, McAllister T and Yang W 2015. In vitro ruminal fermentation of ground and dry-rolled barley grain differing in starch content. Animal Feed Science and Technology 203, 88-94.

Aschenbach JR, Bilk S, Tadesse G, Stumpff F and Gabel G 2009. Bicarbonatedependent and bicarbonate-independent mechanisms contribute to nondiffusive uptake of acetate in the ruminal epithelium of sheep. American Journal of Physiology-Gastrointestinal and Liver Physiology 296, G1098-G1107.

Aschenbach JR, Oswald R and Gabel G 2000. Transport, catabolism and release of histamine in the ruminal epithelium of sheep. Pflügers Archiv: European Journal of Physiology 440, 171-178.

Aschenbach JR, Penner GB, Stumpff F and Gabel G 2011. Ruminant nutrition symposium: role of fermentation acid absorption in the regulation of ruminal $\mathrm{pH}$. Journal of Animal Science 89, 1092-1107.

Aschenbach JR, Seidler T, Ahrens F, Schrodl W, Buchholz I, Garz B, Kruger M and Gabel $G$ 2003. Luminal salmonella endotoxin affects epithelial and mast cell function in the proximal colon of pigs. Scandinavian Journal of Gastroenterology 38, 719-726.

Atkinson 0 2014. Prevalence of subacute ruminal acidosis (SARA) on UK dairy farms. Cattle Practice 22, 1-9.

Bauman DE and Griinari JM 2003. Nutritional regulation of milk fat synthesis. Annual Review of Nutrition 23, 203-227.

Baumann $\mathrm{H}$ and Gauldie J 1994. The acute phase response. Immunology Today $15,74-80$.

Bergen WG and Bates DB 1984. Ionophores - their effect on production efficiency and mode of action. Journal of Animal Science 58, 1465-1483.

Bertok $L$ 1998. Effect of bile acids on endotoxin in vitro and in vivo (physicochemical defense): bile deficiency and endotoxin translocation. Annals of the New York Academy of Sciences 851, 408-410.

Bhatti SA and Firkins JL 1995. Kinetics of hydration and functional specific gravity of fibrous feed by-products. Journal of Animal Science 73, 1449-1458. Bilal MS, Abaker JA, ul Abdin Z, Xu T, Dai H, Zhang K, Liu X and Shen X 2016. Lipopolysaccharide derived from the digestive tract triggers an inflammatory response in the uterus of mid-lactating dairy cows during SARA. BMC Veterinary Research 12, 284

Bramley E, Lean IJ, Fulkerson WJ, Stevenson MA, Rabiee AR and Costa ND 2008. The definition of acidosis in dairy herds predominantly fed on pasture and concentrates. Journal of Dairy Science 91, 308-321.

Braun U, Zurcher S and Hassig M 2015. Evaluation of eating and rumination behaviour in 300 cows of three different breeds using a noseband pressure sensor. BMC Veterinary Research 11, 231.

Brulc JM, Antonopoulos DA, Berg Miller ME, Wilson MK, Yannarell AC, Dinsdale EA, Edwards RE, Frank ED, Emerson JB, Wacklin P, Coutinho PM, Henrissat B, Nelson KE and White BA 2009. Gene-centric metagenomics of the fiberadherent bovine rumen microbiome reveals forage specific glycoside hydrolases. Proceedings of the National Academy of Sciences 106, 1948-1953.

Burrin DG and Britton RA 1986. Response to monensin in cattle during subacute acidosis. Journal of Animal Science 63, 888-893. 
Chang G, Zhang K, Xu T, Jin D, Guo J, Zhuang S and Shen X 2015. Epigenetic mechanisms contribute to the expression of immune related genes in the livers of dairy cows fed a high concentrate diet. PLOS ONE 10, e0123942.

Chaucheyras-Durand F, Walker ND and Bach A 2008. Effects of active dry yeasts on the rumen microbial ecosystem: past, present and future. Animal Feed Science and Technology 145, 5-26.

Chiquette J, Lagrost J, Girard CL, Talbot G, Li S, Plaizier JC and Hindrichsen IK 2015. Efficacy of the direct-fed microbial Enterococcus faecium alone or in combination with Saccharomyces cerevisiae or Lactococcus lactis during induced subacute ruminal acidosis. Journal of Dairy Science 98, 190-203.

Chow JM and Russell JB 1990. Effect of ionophores and $\mathrm{pH}$ on growth of Streptococcus bovis in batch and continuous culture. Applied and Environmental Microbiology 56, 1588-1593.

Christon R, Meslin JC, Thevenoux J, Linard A, Leger CL and Delpal S 1991. Effects of a low dietary linoleic acid level on intestinal morphology and enterocyte brush border membrane lipid composition. Reproduction, Nutrition, Development 31, 691-701.

Clayton EH, Hansch E, Huijnen PTAJ and Rowe JB 1996. Controlling methane production with virginiamycin. Animal production in Australia. Proceedings of the Australian Society of Animal Production 21, 239-242.

Colman E, Khafipour E, Vlaeminck B, De Baets B, Plaizier JC and Fievez V 2013. Grain-based versus alfalfa-based subacute ruminal acidosis induction experiments: similarities and differences between changes in milk fatty acids. Journal of Dairy Science 96, 4100-4111.

Dann HM 2010. Feeding low-starch diets to lactating dairy cows. In Proceedings: 21st Florida Ruminant Nutrition Symposium, 1st Symposium, 2-3 February 2010, Gainesville, FL, USA, pp. 80-91.

Danscher AM, Li S, Andersen PH, Khafipour E, Kristensen NB and Plaizier JC 2015. Indicators of induced subacute ruminal acidosis (SARA) in Danish Holstein cows. Acta Veterinaria Scandinavica 57, 39.

Dengler F, Rackwitz R, Benesch F, Pfannkuche H and Gäbel G 2013. Bicarbonate-dependent transport of acetate and butyrate across the basolateral membrane of sheep rumen epithelium. Acta Physiologica 210, 403-414.

Dennis SM, Nagaraja TG and Bartley EE 1981. Effect of lasalocid or monensin on lactate-producing or using rumen bacteria. Journal of Animal Science 52, 418-426.

Derakhshani H, De Buck J, Mortier R, Barkema HW, Krause DO and Khafipour E 2016. The features of fecal and ileal mucosa-associated microbiota in dairy calves during early infection with Mycobacterium avium subspecies paratuberculosis. Frontiers in Microbiology 7, 426.

Derrien M and van Hylckama Vlieg JE 2015. Fate, activity, and impact of ingested bacteria within the human gut microbiota. Trends in Microbiology 23 , 354-366.

DeVries TJ and Chevaux E 2014. Modification of the feeding behavior of dairy cows through live yeast supplementation. Journal of Dairy Science 97, 6499-6510.

Dionissopoulos L, Laarman AH, AlZahal 0, Greenwood SL, Steele MA, Plaizier JC, Matthews JC and McBride BW 2013. Butyrate-mediated genomic changes involved in non-specific host defenses, matrix remodeling and the immune response in the rumen epithelium of cows afflicted with subacute ruminal acidosis. American Journal of Animal and Veterinary Sciences 8, 8-27.

Dionissopoulos L, Steele M, AIZahal O and McBride B 2012. Adaptation to high grain diets proceeds through minimal immune system stimulation and differences in extracellular matrix protein expression in a model of subacute ruminal acidosis in non-lactating dairy cows. American Journal of Animal and Veterinary Sciences 7, 84-91.

Duffield T, Plaizier JC, Fairfield A, Bagg R, Vessie G, Dick P, Wilson J, Aramini J and $\mathrm{McBride} B$ 2004. Comparison of techniques for measurement of rumen $\mathrm{pH}$ in lactating dairy cows. Journal of Dairy Science 87, 59-66.

Duffield TF, Rabiee AR and Lean IJ 2008. A meta-analysis of the impact of monensin in lactating dairy cattle. Part 2. Production effects. Journal of Dairy Science 91, 1347-1360.

Edwards JE, McEwan NR, McKain N, Walker N and Wallace RJ 2005. Influence of flavomycin on ruminal fermentation and microbial populations in sheep. Microbiology 151, 717-725.

El Kaoutari A, Armougom F, Gordon Jl, Raoult D and Henrissat B 2013. The abundance and variety of carbohydrate-active enzymes in the human gut microbiota. Nature Reviews Microbiology 11, 497-504.
Emmanuel DG, Madsen KL, Churchill TA, Dunn SM and Ametaj BN 2007. Acidosis and lipopolysaccharide from Escherichia coli B:055 cause hyperpermeability of rumen and colon tissues. Journal of Dairy Science 90, 5552-5557. Enemark JMD 2008. The monitoring, prevention and treatment of sub-acute ruminal acidosis (SARA): a review. Veterinary Journal 176, 32-43.

Enjalbert F, Videau $Y$, Nicot MC and Troegeler-Meynadier A 2008. Effects of induced subacute ruminal acidosis on milk fat content and milk fatty acid profile. Journal of Animal Physiology and Animal Nutrition 92, 284-291.

Enomoto N, Ikejima K, Yamashina S, Hirose M, Shimizu H, Kitamura T, Takei Y, Sato $\mathrm{N}$ and Thurman RG 2001. Kupffer cell sensitization by alcohol involves increased permeability to gut-derived endotoxin. Alcoholism, Clinical and Experimental Research 25, 51S-54S.

Erasmus LJ, Botha PM and Kistner A 1992. Effect of yeast culture supplement on production, rumen fermentation, and duodenal nitrogen flow in dairy cows. Journal of Dairy Science 75, 3056-3065.

Erdman RA 1988. Dietary buffering requirements of the lactating dairy cow: a review. Journal of Dairy Science 71, 3246-3266.

Everts RE, Band MR, Liu ZL, Kumar CG, Liu L, Loor JJ, Oliveira R and Lewin HA 2005. A 7872 CDNA microarray and its use in bovine functional genomics. Veterinary Immunology and Immunopathology 105, 235-245.

Fairfield A, Plaizier J, Duffield T, Lindinger M, Bagg R, Dick P and McBride B 2007. Effects of prepartum administration of a monensin controlled release capsule on rumen $\mathrm{pH}$, feed intake, and milk production of transition dairy cows. Journal of Dairy Science 90, 937-945.

Fernando SC, Purvis HT, Najar FZ, Sukharnikov LO, Krehbiel CR and Nagaraja TG 2010. Rumen microbial population dynamics during adaptation to a highgrain diet. Applied and Environmental Microbiology 76, 7482-7490.

Flint $\mathrm{HJ}$ and Bayer EA 2008. Plant cell wall breakdown by anaerobic microorganisms from the mammalian digestive tract. Annals of the New York Academy of Sciences 1125, 280-288.

Folke C, Carpenter S, Walker B, Scheffer M, Elmqvist T, Gunderson L and Holling C 2004. Regime shifts, resilience, and biodiversity in ecosystem management. Annual Review of Ecology, Evolution, and Systematics 35, 557-581.

Foster SL, Hargreaves DC and Medzhitov R 2007. Gene-specific control of inflammation by TLR-induced chromatin modifications. Nature 447, 972-978. Gabel G, Aschenbach JR and Muller F 2002. Transfer of energy substrates across the ruminal epithelium: implications and limitations. Animal Health Research Reviews 3, 15-30.

Gao X and Oba M 2016. Characteristics of dairy cows with a greater or lower risk of subacute ruminal acidosis: volatile fatty acid absorption, rumen digestion, and expression of genes in rumen epithelial cells. Journal of Dairy Science 99, 8733-8745.

Garrett EF, Pereira MN, Nordlund KV, Armentano LE, Goodger WJ and Oetzel GR 1999. Diagnostic methods for the detection of subacute ruminal acidosis in dairy cows. Journal of Dairy Science 82, 1170-1178.

Godfrey S, Rowe J, Thorniley G, Boyce M and Speijers E 1995. Virginiamycin to protect sheep fed wheat, barley or oats from grain poisoning under simulated drought feeding conditions. Australian Journal of Agricultural Research 46, 393-401.

Goldansaz SA, Guo AC, Sajed T, Steele MA, Plastow GS and Wishart DS 2017. Livestock metabolomics and the livestock metabolome: a systematic review. PLOS ONE 12, e0177675.

Golder HM 2014. Increased understandings of ruminal acidosis in dairy cattle. PhD thesis, The University of Sydney, Sydney, Australia.

Golder HM, Celi P and Lean IJ 2014a. Ruminal acidosis in 21-month-old Holstein heifer. Canadian Veterinary Journal 55, 559-564.

Golder HM, Celi P, Rabiee AR and Lean IJ 2014b. Effects of feed additives on rumen and blood profiles during a starch and fructose challenge. Journal of Dairy Science 97, 985-1004.

Golder HM, Denman SE, McSweeney C, Wales WJ, Auldist MJ, Wright MM, Marett LC, Greenwood JS, Hannah MC, Celi P, Bramley E and Lean IJ 2014c. Effects of partial mixed rations and supplement amounts on milk production and composition, ruminal fermentation, bacterial communities, and ruminal acidosis. Journal of Dairy Science $97,5763-5785$.

Golder HM and Lean IJ 2016. A meta-analysis of lasalocid effects on rumen measures, beef and dairy performance, and carcass traits in cattle. Journal of Animal Science 94, 306-326. 
Gorka P, Schurmann BL, Walpole ME, Blonska A, Li S, Plaizier JC, Kowalski ZM and Penner GB 2017. Effect of increasing the proportion of dietary concentrate on gastrointestinal tract measurements and brush border enzyme activity in Holstein steers. Journal of Dairy Science 100, 4539-4551.

Gott PN, Hogan JS and Weiss WP 2015. Effects of various starch feeding regimens on responses of dairy cows to intramammary lipopolysaccharide infusion. Journal of Dairy Science 98, 1786-1796.

Gozho GN, Krause DO and Plaizier JC 2007. Ruminal lipopolysaccharide concentration and inflammatory response during grain-induced subacute ruminal acidosis in dairy cows. Journal of Dairy Science 90, 856-866.

Graham C and Simmons NL 2005. Functional organization of the bovine rumen epithelium. American Journal of Physiology-Regulatory, Integrative and Comparative Physiology 288, R173-R181.

Greenwood RH, Morrill JL, Titgemeyer EC and Kennedy GA 1997. A new method of measuring diet abrasion and its effect on the development of the forestomach. Journal of Dairy Science 80, 2534-2541.

Gressley TF, Hall MB and Armentano LE 2011. Ruminant nutrition symposium: productivity, digestion, and health responses to hindgut acidosis in ruminants. Journal of Animal Science 89, 1120-1130.

Guan H, Wittenberg KM, Ominski KH and Krause DO 2006. Efficacy of ionophores in cattle diets for mitigation of enteric methane. Journal of Animal Science 84, 1896-1906.

Guo J, Chang G, Zhang K, Xu L, Jin D, Bilal MS and Shen X 2017. Rumen-derived lipopolysaccharide provoked inflammatory injury in the liver of dairy cows fed a high-concentrate diet. Oncotarget 8, 46769-46780.

Hall MB and Weimer PJ 2016. Divergent utilization patterns of grass fructan, inulin, and other nonfiber carbohydrates by ruminal microbes. Journal of Dairy Science 99, 245-257.

Haney ME Jr and Hoehn MM 1967. Monensin, a new biologically active compound. I. Discovery and isolation. Antimicrobial Agents and Chemotherapy 7, 349-352.

Henderson G, Cox F, Ganesh S, Jonker A, Young W and Janssen PH 2015. Rumen microbial community composition varies with diet and host, but a core microbiome is found across a wide geographical range. Scientific Reports 5, 14567.

Hollmann M, Miller I, Hummel K, Sabitzer S, Metzler-Zebeli BU, Razzazi-Fazeli E and Zebeli Q 2013. Downregulation of cellular protective factors of rumen epithelium in goats fed high energy diet. PLOS ONE 8, e81602.

Horton GMJ and Nicholson HH 1980. Rumen metabolism and feedlot responses by steers fed tylosin and monensin. Canadian Journal of Animal Science 60, 919-924.

Hu W and Murphy MR 2005. Statistical evaluation of early- and mid-lactation dairy cow responses to dietary sodium bicarbonate addition. Animal Feed Science and Technology 119, 43-54.

Humblet MF, Guyot H, Boudry B, Mbayahi F, Hanzen C, Rollin F and Godeau JM 2006. Relationship between haptoglobin, serum amyloid $A$, and clinical status in a survey of dairy herds during a 6-month period. Veterinary Clinical Pathology 35, 188-193.

Hurley JC 1995. Endotoxemia: methods of detection and clinical correlates. Clinical Microbiol Reviews 8, 268-292.

Jacobsen S, Andersen PH, Toelboell T and Heegaard PMH 2004. Dose dependency and individual variability of the lipopolysaccharide-induced bovine acute phase protein response. Journal of Dairy Science 87, 3330-3339.

Jami E and Mizrahi I 2012. Composition and similarity of bovine rumen microbiota across individual animals. PLoS ONE 7, e33306.

Jin D, Chang G, Zhang K, Guo J, Xu T and Shen X 2016. Rumen-derived lipopolysaccharide enhances the expression of lingual antimicrobial peptide in mammary glands of dairy cows fed a high-concentrate diet. BMC Veterinary Research 12, 128.

Johansson ME, Ambort D, Pelaseyed T, Schütte A, Gustafsson JK, Ermund A, Subramani DB, Holmén-Larsson JM, Thomsson KA and Bergström JH 2011. Composition and functional role of the mucus layers in the intestine. Cellular and Molecular Life Sciences 68, 3635.

Karmin O, Rodriguez-Lecompte J, Ominski KH, Li S, Woyengo T, Kroeker AD and Plaizier J 2011. Effect of grain- and alfalfa pellet-induced sub-acute rumen acidosis (SARA) challenges on oxidative stress in dairy cows. Canadian Journal of Animal Science 91, 512-513.
Kasumov T, Li L, Li M, Gulshan K, Kirwan JP, Liu X, Previs S, Willard B, Smith JD and McCullough A 2015. Ceramide as a mediator of non-alcoholic fatty liver disease and associated atherosclerosis. PLOS ONE 10, e0126910.

Kenney NM, Vanzant ES, Harmon DL and McLeod KR 2015. Direct-fed microbials containing lactate-producing bacteria influence ruminal fermentation but not lactate utilization in steers fed a high-concentrate diet. Journal of Animal Science 93, 2336-2348.

Khafipour E, Krause D and Plaizier J 2009a. Alfalfa pellet-induced subacute ruminal acidosis in dairy cows increases bacterial endotoxin in the rumen without causing inflammation. Journal of Dairy Science 92, 1712-1724.

Khafipour E, Krause D and Plaizier J 2009b. A grain-based subacute ruminal acidosis challenge causes translocation of lipopolysaccharide and triggers inflammation. Journal of Dairy Science 92, 1060-1070.

Khafipour E, Li S, Plaizier JC and Krause DO 2009c. Rumen microbiome composition determined using two nutritional models of subacute ruminal acidosis. Applied and Environmental Microbiology 75, 7115-7124.

Khafipour E, Li S, Tun H, Derakhshani H, Moossavi S and Plaizier J 2016. Effects of grain feeding on microbiota in the digestive tract of cattle. Animal Frontiers 6, 13-19.

Khorrami B, Vakili A, Danesh Mesgaran M and Klevenhusen F 2015. Thyme and cinnamon essential oils: potential alternatives for monensin as a rumen modifier in beef production systems. Animal Feed Science and Technology 200, 8-16.

Klassing KC and Iseri VC 2013. Recent advances in understanding the interactions between nutrition and immunity in farm animals. In 4th International Symposium on Energy and Protein Metabolism and Nutrition, Sacramento, CA USA (ed. JW Oltjen, E Kebreab and H Lapierre), EAAP Publication No. 134, pages 353-360, Rome, Italy.

Kleen JL, Hooijer GA, Rehage J and Noordhuizen JP 2003. Subacute ruminal acidosis (SARA): a review. Journal of Veterinary Medicine. A, Physiology, Pathology, Clinical Medicine 50, 406-414.

Kleen JL, Hooijer GA, Rehage J and Noordhuizen JP 2009. Subacute ruminal acidosis in Dutch dairy herds. Veterinary Record 164, 681-683.

Kleen JL, Upgang L and Rehage J 2013. Prevalence and consequences of subacute ruminal acidosis in German dairy herds. Acta Veterinaria Scandinavica $55,48$.

Klieve A, Hennessy D, Ouwerkerk D, Forster R, Mackie R and Attwood G 2003. Establishing populations of Megasphaera elsdenii YE 34 and Butyrivibrio fibrisolvens YE 44 in the rumen of cattle fed high grain diets. Journal of Applied Microbiology 95, 621-630.

Koropatkin NM, Cameron EA and Martens EC 2012. How glycan metabolism shapes the human gut microbiota. Nature Reviews Microbiology 10, 323-335. Krause KM and Oetzel GR 2005. Inducing subacute ruminal acidosis in lactating dairy cows. Journal of Dairy Science 88, 3633-3639.

Krehbiel CR, Rust SR, Zhang G and Gilliland SE 2003. Bacterial direct-fed microbials in ruminant diets: performance response and mode of action. Journal of Animal Science 81, E120-E132.

Laarman AH, Pederzolli RA, Wood KM, Penner GB and McBride BW 2016. Effects of subacute ruminal acidosis and low feed intake on short-chain fatty acid transporters and flux pathways in Holstein steers. Journal of Animal Science 94, 3729-3737.

Lean IJ, Golder HM, Black JL, King R and Rabiee AR 2013. In vivo indices for predicting acidosis risk of grains in cattle: comparison with in vitro methods. Journal of Animal Science 91, 2823-2835.

Lean IJ, Golder HM and Hall MB 2014. Feeding, evaluating, and controlling rumen function. Veterinary Clinics of North America: Food Animal Practice 30, $539-575$.

Lean IJ, Wade LK, Curtis MA and Porter J 2000. New approaches to control of ruminal acidosis in dairy cattle. Australasian Journal of Animal Science 13 (suppl), 266-269.

LeBlanc SJ, Leslie KE and Duffield TF 2005. Metabolic predictors of displaced abomasum in dairy cattle. Journal of Dairy Science 88, 159-170.

Leeuw K, Siebrits F, Henning P and Meissner H 2009. Effect of Megasphaera elsdenii NCIMB 41125 drenching on health and performance of steers fed high and low roughage diets in the feedlot. South African Journal of Animal Science 39, 337-348.

Lehloenya KV, Krehbiel CR, Mertz KJ, Rehberger TG and Spicer LJ 2008. Effects of propionibacteria and yeast culture fed to steers on nutrient intake and site and extent of digestion. Journal of Dairy Science 91, 653-662. 
Plaizier, Danesh Mesgaran, Derakhshani, Golder, Khafipour, Kleen, Lean, Loor, Penner and Zebeli

Leng R 2014. Interactions between microbial consortia in biofilms: a paradigm shift in rumen microbial ecology and enteric methane mitigation. Animal Production Science 54, 519-543.

Levin J and Bang F 1968. Clottable protein in Limulus; its localization and kinetics of its coagulation by endotoxin. Thrombosis et diathesis haemorrhagica 19, 186-197.

Ley RE, Turnbaugh PJ, Klein S and Gordon JI 2006. Microbial ecology: human gut microbes associated with obesity. Nature 444, 1022-1023.

Li M, Penner GB, Hernandez-Sanabria E, Oba M and Guan LL 2009. Effects of sampling location and time, and host animal on assessment of bacterial diversity and fermentation parameters in the bovine rumen. Journal of Applied Microbiology 107, 1924-1934.

Li S, Khafipour E, Krause DO, Kroeker A, Rodriguez-Lecompte JC, Gozho GN and Plaizier JC 2012. Effects of subacute ruminal acidosis challenges on fermentation and endotoxins in the rumen and hindgut of dairy cows. Journal of Dairy Science 95, 294-303.

Li S, Yoon I, Scott M, Khafipour E and Plaizier JC 2016. Impact of Saccharomyces cerevisiae fermentation product and subacute ruminal acidosis on production, inflammation, and fermentation in the rumen and hindgut of dairy cows. Animal Feed Science and Technology 211, 50-60.

Lunn D, Mutsvangwa T, Odongo N, Duffield T, Bagg R, Dick P, Vessie G and McBride $B$ 2005. Effect of monensin on meal frequency during sub-acute ruminal acidosis in dairy cows. Canadian Journal of Animal Science 85, 247-249.

Malekkhahi M, Tahmasbi AM, Naserian AA, Danesh Mesgaran M, Kleen J and Parand A 2015. Effects of essential oils, yeast culture and malate on rumen fermentation, blood metabolites, growth performance and nutrient digestibility of Baluchi lambs fed high-concentrate diets. Journal of Animal Physiology and Animal Nutrition 99, 221-229.

Malhi M, Gui H, Yao L, Aschenbach JR, Gabel G and Shen Z 2013. Increased papillae growth and enhanced short-chain fatty acid absorption in the rumen of goats are associated with transient increases in cyclin D1 expression after ruminal butyrate infusion. Journal of Dairy Science 96, 7603-7616.

Mao SY, Zhang RY, Wang DS and Zhu WY 2013. Impact of subacute ruminal acidosis (SARA) adaptation on rumen microbiota in dairy cattle using pyrosequencing. Anaerobe 24, 12-19.

Matthé A, Lebzien P, Hric I, Flachowsky G and Sommer A 2001. Effect of starch application into the proximal duodenum of ruminants on starch digestibility in the small and total intestine. Archives of Animal Nutrition 55, 351-369.

McAllister T, Beauchemin K, Alazzeh A, Baah J, Teather R and Stanford K 2011. Review: the use of direct fed microbials to mitigate pathogens and enhance production in cattle. Canadian Journal of Animal Science 91, 193-211.

McCann JC, Wickersham TA and Loor JJ 2014. High-throughput methods redefine the rumen microbiome and its relationship with nutrition and metabolism. Bioinformatics and Biology Insights 8, 109.

Meissner $\mathrm{HH}$, Henning $\mathrm{PH}$, Leeuw $\mathrm{KJ}$, Hagg FM, Horn $\mathrm{CH}$, Kettunen $\mathrm{A}$ and Apajalahti JHA 2014. Efficacy and mode of action of selected non-ionophore antibiotics and direct-fed microbials in relation to Megasphaera elsdenii NCIMB 41125 during in vitro fermentation of an acidosis-causing substrate. Livestock Science 162, 115-125.

Mertens DR 1997. Creating a system for meeting the fiber requirements of dairy cows. Journal of Dairy Science 80, 1463-1481.

Metzler-Zebeli BU, Schmitz-Esser S, Klevenhusen F, Podstatzky-Lichtenstein L, Wagner M and Zebeli Q 2013. Grain-rich diets differently alter ruminal and colonic abundance of microbial populations and lipopolysaccharide in goats. Anaerobe 20, 65-73.

Minuti A, Ahmed S, Trevisi E, Piccioli-Cappelli F, Bertoni G, Jahan N and Bani P 2014. Experimental acute rumen acidosis in sheep: consequences on clinical, rumen, and gastrointestinal permeability conditions and blood chemistry. Journal of Animal Science 92, 3966-3977.

Mojtahedi M and Danesh Mesgaran M 2011. Effects of the inclusion of dried molassed sugar beet pulp in a low-forage diet on the digestive process and blood biochemical parameters of Holstein steers. Livestock Science 141, 95-103.

Morgante M, Stelletta C, Berzaghi P, Gianesella M and Andrighetto I 2007. Subacute rumen acidosis in lactating cows: an investigation in intensive Italian dairy herds. Journal of Animal Physiology and Animal Nutrition 91, 226-234.

Moya D, Calsamiglia S, Ferret A, Blanch M, Fandiño Jl, Castillejos L and Yoon I 2009. Effects of dietary changes and yeast culture (Saccharomyces cerevisiae) on rumen microbial fermentation of Holstein heifers. Journal of Animal Science 87, 2874-2881.
Mullenax CH, Keeler RF and Allison MJ 1966. Physiologic responses of ruminants to toxic factors extracted from rumen bacteria and rumen fluid. American Journal of Veterinary Research 27, 857-868.

Mulligan FJ and Doherty ML 2008. Production diseases of the transition cow. The Veterinary Journal 176, 3-9

Nagaraja TG, Avery TB, Bartley EE, Galitzer SJ and Dayton AD 1981. Prevention of lactic acidosis in cattle by lasalocid or monensin. Journal of Animal Science 53, 206-216.

Nagaraja TG, Avery TB, Bartley EE, Roof SK and Dayton AD 1982. Effect of lasalocid, monensin or thiopeptin on lactic acidosis in cattle. Journal of Animal Science 54, 649-658.

Nagaraja TG, Godfrey SI, Winslow SW and Rowe JB 1995a. Responses in ciliated protozoa and rumen fermentation in sheep supplemented with barley plus virginiamycin. Australian Journal of Agricultural Research 46, 11371147.

Nagaraja TG, Godfrey SI, Winslow SW, Rowe JB and Kemp KE 1995b. Effect of virginiamycin on ruminal fermentation in faunated or ciliate-free sheep overfed with barley grain. Small Ruminant Research 17, 1-8.

Nagaraja TG and Lechtenberg KF 2007. Acidosis in feedlot cattle. Veterinary Clinics of North America: Food Animal Practice 23, 333-350.

Nagaraja TG, Sun YD, Wallace N, Kemp KE and Parrott CJ 1999. Effects of tylosin on concentrations of Fusobacterium necrophorum and fermentation products in the rumen of cattle fed a high-concentrate diet. American Journal of Veterinary Research 60, 1061-1065.

Nagaraja TG and Taylor M 1987. Susceptibility and resistance of ruminal bacteria to antimicrobial feed additives. Applied and Environmental Microbiology 53, 1620-1625

Nagaraja TG, Taylor MB, Harmon DL and Boyer JE 1987. In vitro lactic acid inhibition and alterations in volatile fatty acid production by antimicrobial feed additives. Journal of Animal Science 65, 1064-1076.

Nakamura MT, Yudell BE and Loor JJ 2014. Regulation of energy metabolism by long-chain fatty acids. Progress in Lipid Research 53, 124-144.

Netea MG, van Deuren M, Kullberg BJ, Cavaillon JM and Van der Meer JW 2002. Does the shape of lipid A determine the interaction of LPS with Toll-like receptors? Trends in Immunology 23, 135-139.

Nocek JE 1997. Bovine acidosis: implications on laminitis. Journal of Dairy Science 80, 1005-1028.

O'Grady L, Doherty ML and Mulligan FJ 2008. Subacute ruminal acidosis (SARA) in grazing Irish dairy cows. The Veterinary Journal 176, 44-49.

Owens FN, Secrist DS, Hill WJ and Gill DR 1998. Acidosis in cattle: a review. Journal of Animal Science 76, 275-286.

Pederzolli RA, Van Kessel AG, Campbell J, Hendrick S, Wood KM and Penner GB 2018. Effect of ruminal acidosis and short-term low feed intake on indicators of gastrointestinal barrier function in Holstein steers. Journal of Animal Science 96, 108-125.

Penner GB, Aschenbach JR, Gäbel G, Rackwitz R and Oba M 2009. Epithelial capacity for apical uptake of short chain fatty acids is a key determinant for intraruminal $\mathrm{pH}$ and the susceptibility to subacute ruminal acidosis in sheep. The Journal of Nutrition 139, 1714-1720.

Penner GB, Aschenbach JR, Wood KM, Walpole ME, Kanafany-Guzman R, Hendrick $S$ and Campbell J 2014. Characterising barrier function among regions of the gastrointestinal tract in Holstein steers. Animal Production Science 54, 1282-1287.

Petri RM, Schwaiger T, Penner GB, Beauchemin KA, Forster RJ, McKinnon JJ and McAllister TA 2013. Characterization of the core rumen microbiome in cattle during transition from forage to concentrate as well as during and after an acidotic challenge. PLoS ONE 8, e83424.

Plaizier J, Garner T, Droppo T and Whiting T 2004. Nutritional practices on Manitoba dairy farms. Canadian Journal of Animal Science 84, 501-509.

Plaizier J, Khafipour E, Li S, Gozho G and Krause D 2012a. Subacute ruminal acidosis (SARA), endotoxins and health consequences. Animal Feed Science and Technology 172, 9-21.

Plaizier JC, Khafipour E, Li S, Gozho GN and Krause DO 2012b. Subacute ruminal acidosis (SARA), endotoxins and health consequences. Animal Feed Science and Technology 172, 9-21.

Plaizier JC, Krause DO, Gozho GN and McBride BW 2008. Subacute ruminal acidosis in dairy cows: the physiological causes, incidence and consequences. Veterinary Journal 176, 21-31. 
Plaizier JC, Li S, Danscher AM, Derakshani H, Andersen PH and Khafipour E 2017. Changes in microbiota in rumen digesta and feces due to a grain-based subacute ruminal acidosis (SARA) challenge. Microbial Ecology 74, 485-495.

Plaizier JC, Li S, Le Sciellour M, Schurmann BL, Górka P and Penner GB 2014. Effects of duration of moderate increases in grain feeding on endotoxins in the digestive tract and acute phase proteins in peripheral blood of yearling calves. Journal of Dairy Science 97, 7076-7084.

Qumar M, Khiaosa-ard R, Klevenhusen F, Plaizier JC and Zebeli Q 2017. Gastrointestinal endotoxin and metabolic responses in cows fed and recovered from two different grain-rich challenges. Livestock Science 203 (suppl. C), 120-123.

Richardson LF, Raun AP, Potter EL, Cooley CO and Rathmacher RP 1976. Effect of monensin on rumen fermentation in vitro and in vivo. Journal of Animal Science 43, 657-664.

Robinson PH 1997. Effect of yeast culture (Saccharomyces cerevisiae) on adaptation of cows to diets postpartum. Journal of Dairy Science 80, 1119-1125.

Rogers JA, Branine ME, Miller CR, Wray MI, Bartle SJ, Preston RL, Gill DR, Pritchard RH, Stilborn RP and Bechtol DT 1995. Effects of dietary virginiamycin on performance and liver abscess incidence in feedlot cattle. Journal of Animal Science 73, 9-20.

Rowe JB and Pethick DW 1994. Starch digestion in ruminants - problems, solutions and opportunities. Proceedings of the Nutrition Society of Australia 18 40-52.

Russell JB and Chow JM 1993. Another theory for the action of ruminal buffer salts: decreased starch fermentation and propionate production. Journal of Dairy Science 76, 826-830.

Russell JB and Dombrowski JB 1980. Effect of pH on the efficiency of growth by pure cultures of rumen bacteria in continuous culture. Applied and Environmental Microbiology 39, 604-610.

Russell JB and Houlihan AJ 2003. Ionophore resistance of ruminal bacteria and its potential impact on human health. FEMS Microbiology Reviews 27, 65-74.

Russell JB and Rychlik JL 2001. Factors that alter rumen microbial ecology. Science 292, 1119-1122.

Saleem F, Ametaj BN, Bouatra S, Mandal R, Zebeli Q, Dunn SM and Wishart DS 2012. A metabolomics approach to uncover the effects of grain diets on rumen health in dairy cows. Journal of Dairy Science 95, 6606-6623.

Satoh M, Ando S, Shinoda T and Yamazaki M 2008. Clearance of bacterial lipopolysaccharides and lipid $A$ by the liver and the role of arginino-succinate synthase. Innate Immunity 14, 51-60.

Saturnino SF, Prado RO, Cunha-Melo JR and Andrade MV 2010. Endotoxin tolerance and cross-tolerance in mast cells involves TLR4, TLR2 and FcepsilonR1 interactions and SOCS expression: perspectives on immunomodulation in infectious and allergic diseases. BMC Infectious Diseases 10, 240.

Senaratne VP, McGeough EJ, Ominski KH and Plaizier JC 2016. 0484 Phosphorus utilization on dairy farms in Manitoba. Journal of Animal Science 94 (suppl. 5) 232-233.

Schlau N, Guan LL and Oba M 2012. The relationship between rumen acidosis resistance and expression of genes involved in regulation of intracellular $\mathrm{pH}$ and butyrate metabolism of ruminal epithelial cells in steers. Journal of Dairy Science 95, 5866-5875.

Schurmann BL, Walpole ME, Gorka P, Ching JC, Loewen ME and Penner GB 2014. Short-term adaptation of the ruminal epithelium involves abrupt changes in sodium and short-chain fatty acid transport. American Journal of PhysiologyRegulatory, Integrative and Comparative Physiology 307, R802-R816.

Schwaiger T, Beauchemin KA and Penner GB 2013a. Duration of time that beef cattle are fed a high-grain diet affects the recovery from a bout of ruminal acidosis: short-chain fatty acid and lactate absorption, saliva production, and blood metabolites. Journal of Animal Science 91, 5743-5753.

Schwaiger T, Beauchemin KA and Penner GB 2013b. The duration of time that beef cattle are fed a high-grain diet affects the recovery from a bout of ruminal acidosis: dry matter intake and ruminal fermentation. Journal of Animal Science 91, 5729-5742.

Seo JK, Kim S-W, Kim MH, Upadhaya SD, Kam DK and Ha JK 2010. Direct-fed microbials for ruminant animals. Asian-Australasian Journal of Animal Sciences $12,1657-1667$.

Shen Z, Seyfert HM, Lohrke B, Schneider F, Zitnan R, Chudy A, Kuhla S, Hammon HM, Blum JW, Martens H, Hagemeister H and Voigt J 2004. An energy-rich diet causes rumen papillae proliferation associated with more IGF type 1 receptors and increased plasma IGF-1 concentrations in young goats. The Journal of Nutrition 134, 11-17.
Shi Y and Weimer PJ 1992. Response surface analysis of the effects of pH and dilution rate on Ruminococcus flavefaciens FD-1 in cellulose-fed continuous culture. Applied and Environmental Microbiology 58, 2583-2591.

Sordillo L and Aitken SL 2009. Impact of oxidative stress on the health and immune function of dairy cattle. Veterinary Immunology and Immunopathology $128,104-109$.

Staples CR and Lough DS 1989. Efficacy of supplemental dietary neutralizing agents for lactating dairy cows. A review. Animal Feed Science and Technology 23, 277-303.

Steele MA, AIZahal O, Hook SE, Croom J and McBride BW 2009. Ruminal acidosis and the rapid onset of ruminal parakeratosis in a mature dairy cow: a case report. Acta Veterinaria Scandinavica 5, 39.

Steele MA, Croom J, Kahler M, AlZahal O, Hook SE, Plaizier K and McBride BW 2011 a. Bovine rumen epithelium undergoes rapid structural adaptations during grain-induced subacute ruminal acidosis. American Journal of Physiology-Regulatory, Integrative and Comparative Physiology 300, R1515-R1523.

Steele MA, Dionissopoulos L, AlZahal O, Doelman J and McBride BW 2012. Rumen epithelial adaptation to ruminal acidosis in lactating cattle involves the coordinated expression of insulin-like growth factor-binding proteins and a cholesterolgenic enzyme. Journal of Dairy Science 95, 318-327.

Steele MA, Penner GB, Chaucheyras-Durand F and Guan LL 2016. Development and physiology of the rumen and the lower gut: targets for improving gut health. Journal of Dairy Science 99, 4955-4966.

Steele MA, Schiestel C, AlZahal O, Dionissopoulos L, Laarman AH, Matthews JC and McBride BW 2015. The periparturient period is associated with structural and transcriptomic adaptations of rumen papillae in dairy cattle. Journal of Dairy Science 98, 2583-2595.

Steele MA, Vandervoort G, AIZahal 0, Hook SE, Matthews JC and McBride BW 2011a. Rumen epithelial adaptation to high-grain diets involves the coordinated regulation of genes involved in cholesterol homeostasis. Physiological Genomics 43, 308-316.

Steele MA, Vandervoort G, AIZahal 0, Hook SE, Matthews JC and McBride BW 2011 b. Rumen epithelial adaptation to high-grain diets involves the coordinated regulation of genes involved in cholesterol homeostasis. Physiological Genomics 43, 308-316

Stefanska B, Nowak W, Komisarek J, Taciak M, Barszcz M and Skomial J 2017. Prevalence and consequence of subacute ruminal acidosis in Polish dairy herds. Journal of Animal Physiology and Animal Nutrition 101, 694-702.

Tafaj M, Junck B, Maulbetsch A, Steingass H, Piepho H and Drochner W 2004. Digesta characteristics of dorsal, middle and ventral rumen of cows fed with different hay qualities and concentrate levels. Archives of Animal Nutrition 58, 325-342.

Tajik J, Nadalian MG, Raoofi A, Mohammadi GR and Bahonar AR 2009. Prevalence of subacute ruminal acidosis in some dairy herds of Khorasan Razavi province, northeast of Iran. Iranian Journal of Veterinary Research 10, 28-32.

Tao S, Duanmu Y, Dong H, Ni Y, Chen J, Shen X and Zhao R 2014. High concentrate diet induced mucosal injuries by enhancing epithelial apoptosis and inflammatory response in the hindgut of goats. PLOS ONE 9, e111596.

Tomlinson JE and Blikslager AT 2004. Interactions between lipopolysaccharide and the intestinal epithelium. Journal of the American Veterinary Medical Association 224, 1446-1452.

Van Soest PJ 1994. Nutritional ecology of the ruminant, 2nd ed. Cornell University Press, Ithaca, NY, USA.

Vyas D, Beauchemin KA and Koenig KM 2015. Using organic acids to control subacute ruminal acidosis and fermentation in feedlot cattle fed a highgrain diet. Journal of Animal Science 93, 3950-3958.

Weimer PJ 2015. Redundancy, resilience, and host specificity of the ruminal microbiota: implications for engineering improved ruminal fermentations. Frontiers in Microbiology 6, 296.

Weimer PJ, Stevenson D, Mertens D and Thomas E 2008. Effect of monensin feeding and withdrawal on populations of individual bacterial species in the rumen of lactating dairy cows fed high-starch rations. Applied Microbiology and Biotechnology 80, 135-145.

Wells JE and Russell JB 1996. Why do many ruminal bacteria die and lyse so quickly? Journal of Dairy Science 79, 1487-1495.

White BA, Lamed R, Bayer EA and Flint HJ 2014. Biomass utilization by gut microbiomes. Annual Review of Microbiology 68, 279-296. 


\section{Plaizier, Danesh Mesgaran, Derakhshani, Golder, Khafipour, Kleen, Lean, Loor, Penner and Zebeli}

Wood KM, Palmer SI, Steele MA, Metcalf JA and Penner GB 2015. The influence of age and weaning on permeability of the gastrointestinal tract in Holstein bull calves. Journal of Dairy Science 98, 7226-7237.

Xu T, Cardoso FC, Pineda A, Trevisi E, Shen X, Rosa F, Osorio JS and Loor JJ 2017. Grain challenge affects systemic and hepatic molecular biomarkers of inflammation, stress, and metabolic responses to a greater extent in Holstein than Jersey cows. Journal of Dairy Science 100, 9153-9162.

Yoon IK and Stern MD 1995. Influence of direct-fed microbials on ruminal microbial fermentation and performance of ruminants: a review. AsianAustralasian Journal of Animal Sciences 8, 533-555.

Zaneveld J, Turnbaugh PJ, Lozupone C, Ley RE, Hamady M, Gordon JI and Knight $\mathrm{R} 2008$. Host-bacterial coevolution and the search for new drug targets. Current Opinion in Chemical Biology 12, 109-114.

Zebeli Q, Dijkstra J, Tafaj M, Steingass H, Ametaj BN and Drochner W 2008. Modeling the adequacy of dietary fiber in dairy cows based on the responses of ruminal $\mathrm{pH}$ and milk fat production to composition of the diet. Journal of Dairy Science 91, 2046-2066.

Zebeli Q, Aschenbach JR, Tafaj M, Boguhn J, Ametaj BN and Drochner W 2012a. Invited review: role of physically effective fiber and estimation of dietary fiber adequacy in high-producing dairy cattle. Journal of Dairy Science 95, 1041-1056.
Zebeli Q, Metzler-Zebeli BU and Ametaj BN 2012b. Meta-analysis reveals threshold level of rapidly fermentable dietary concentrate that triggers systemic inflammation in cattle. Journal of Dairy Science 95, 2662-2672.

Zhang S, Albornoz RI, Aschenbach JR, Barreda DR and Penner GB 2013a. Shortterm feed restriction impairs the absorptive function of the reticulo-rumen and total tract barrier function in beef cattle. Journal of Dairy Science 91, 1685-1695.

Zhang S, Aschenbach JR, Barreda DR and Penner GB 2013b. Recovery of absorptive function of the reticulo-rumen and total tract barrier function in beef cattle after short-term feed restriction. Journal of Dairy Science 91, 1696-1706. Zhang K, Chang G, Xu T, Xu L, Guo J, Jin D and Shen X 2016. Lipopolysaccharide derived from the digestive tract activates inflammatory gene expression and inhibits casein synthesis in the mammary glands of lactating dairy cows. Oncotarget 7, 9652-9665.

Zhang R, Zhu W, Jiang L and Mao S 2017. Comparative metabolome analysis of ruminal changes in Holstein dairy cows fed low-or high-concentrate diets. Metabolomics 13, 74.

Zhang R, Zhu W and Mao S 2016. High-concentrate feeding upregulates the expression of inflammation-related genes in the ruminal epithelium of dairy cattle. Journal of Animal Science and Biotechnology 7, 42-55. 